\title{
Identifying Novel Roles for Peptidergic Signaling in Mice
}

\author{
Kathryn G. Powers ${ }^{1}$; Xin-Ming Ma ${ }^{1}$; Betty A. Eipper ${ }^{1,2}$; Richard E. Mains ${ }^{1 *}$ \\ Departments of Neuroscience ${ }^{1}$ and Molecular Biology and Biophysics ${ }^{2}$ \\ University of Connecticut Health Center \\ Farmington CT 06030-3401 \\ ORCID: 0000-0003-1154-1331 (REM), 0000-0003-1171-5557 (BAE)
}

${ }^{*}$ Correspondence: Richard E. Mains, Department of Neuroscience, University of Connecticut Health Center, Farmington CT 06030-3401. 860-679-8894

Authors contributions: KGP, BAE and REM designed experiments; KGP, XMM, BAE and REM performed research; KGP, XMM, BAE and REM analyzed data; and KGP, BAE and REM wrote the paper.

Conflicts: The authors declare no conflict of interest.

Key words: amidation, atrium, excitatory neurons, atrial natriuretic peptide, anxiety, temperature control, cocaine, RNAseq, clock genes, apelin

\section{ABSTRACT}

Despite accumulating evidence demonstrating the essential roles played by neuropeptides, it has proven challenging to use this information to develop therapeutic strategies. Peptidergic signaling can involve juxtacrine, paracrine, endocrine and neuronal signaling, making it difficult to define physiologically important pathways. One of the final steps in the biosynthesis of many neuropeptides requires a single enzyme, peptidylglycine $\alpha$-amidating monooxygenase (PAM), and lack of amidation renders most of these peptides biologically inert. PAM, an ancient integral membrane enzyme that traverses the biosynthetic and endocytic pathways, also affects cytoskeletal organization and gene expression. While mice, zebrafish and flies lacking $\operatorname{Pam}\left(\mathrm{Pam}^{\mathrm{KO} / \mathrm{KO}}\right)$ are not viable, we reasoned that cell-type specific elimination of Pam expression would generate mice that could be screened for physiologically important and tissue-specific deficits. Pam ${ }^{\mathrm{cKO} / \mathrm{cKO}}$ mice, with loxP sites flanking the 2 exons deleted in the global $\mathrm{Pam}^{\mathrm{KO} / \mathrm{KO}}$ mouse, were indistinguishable from wildtype mice. Eliminating Pam expression in excitatory forebrain neurons reduced anxiety-like behavior, increased locomotor responsiveness to cocaine and improved thermoregulation in the cold. A number of amidated peptides play essential roles in each of these behaviors. Although atrial natriuretic peptide (ANP) is not amidated, Pam expression in the atrium exceeds levels in any other tissue. Eliminating Pam expression in cardiomyocytes increased anxiety-like behavior and improved thermoregulation. Atrial and serum levels of ANP fell sharply in $\mathrm{Pam}^{\mathrm{Myh} 6-\mathrm{ckO} / \mathrm{cKO}}$ mice and RNASeq analysis identified changes in gene expression in pathways related to cardiac function. Use of this screening platform should facilitate the development of new therapeutic approaches targeted to peptidergic pathways. 


\section{SIGNIFICANCE}

Peptidergic signaling, which plays key roles in the many pathways that control thermoregulation, salt and water balance, metabolism, anxiety, pain perception and sexual reproduction, is essential for the maintenance of homeostasis. Despite the fact that peptides generally signal through $\mathrm{G}$ protein coupled receptors, it has proven difficult to use knowledge about peptide synthesis, storage and secretion to develop effective therapeutics. Our goal was to develop an in vivo bioassay system that would reveal physiologically meaningful deficits associated with disturbed peptidergic signaling. We did so by developing a system in which an enzyme essential for the production of many bioactive peptides could be eliminated in a tissue-specific manner.

\section{INTRODUCTION}

Peptidergic signaling plays a key role in the vertebrate nervous system and in animals such as Trichoplax adhaerens, which lack neurons and muscles (1). Transcripts encoding putative $T$. adhaerens preproneuropeptides are expressed in a cell-type specific manner, and peptides that could be derived from them govern movement and contractile behavior (2). Acting as co-transmitters and neuromodulators in organisms with a nervous system, neuropeptides play critical roles in the complex pathways that control pain perception, mating behaviors, anxiety, appetite and metabolism (3).

Bioactive neuropeptide synthesis in Trichoplax and mammals involves a similar set of post-translational modifications, each of which occurs in the lumen of the secretory pathway (4-7). The bioactive peptides are stored in secretory granules and released in response to an appropriate stimulus. The vast majority of neuropeptides act through G protein coupled receptors (GPCRs), which may be located close to or far from the site at which the bioactive peptide is released (8). Neuropeptides were identified using bioassays, biochemical paradigms, screens for GPCR ligands and genetic selections. Some bioactive peptides, such as neuropeptide $\mathrm{Y}$ (NPY), were identified by the presence of a common post-translational modification, $\mathrm{C}$-terminal amidation, which is often essential for bioactivity $(8,9)$.

Preproneuropeptides that yield amidated products encode precursors that generate a peptidylglycine intermediate. Peptidylglycine $\alpha$-amidating monooxygenase (PAM; E.C. 1.4.17.3) catalyzes the two step conversion of the penultimate residue of its peptidylglycine substrate into an $\alpha$-amide, releasing glyoxylate (8). Cell culture experiments have revealed additional roles for PAM in regulating cytoskeletal organization, secretagogue responsiveness and gene expression (10). PAM knockout mice $\left(\mathrm{Pam}^{\mathrm{KO} / \mathrm{KO}}\right)$, zebrafish and Drosophila are not viable (11-13). Pam $^{\mathrm{KO} / \mathrm{KO}}$ mouse embryos develop pericardial edema, have a poorly developed yolk sac vasculature and do not survive beyond the second week of gestation (11). Mice with a single copy of Pam are sensitive to seizures, exhibit increased anxiety-like behavior and cannot maintain body temperature in the cold (14). Genetic studies indicate that PAM is associated with diabetes, Alzheimer disease, Parkinson disease, hypertension and pituitary tumors (reviewed in $(8))$.

We hypothesized that generation of a mouse line in which Pam expression can be eliminated in a cell type-specific manner would facilitate the identification of behaviors and metabolic pathways in which neuropeptides and PAM play significant roles. LoxP sites were placed around the exons eliminated in the $\mathrm{Pam}^{\mathrm{KO} / \mathrm{KO}}$ mouse (11), generating the Pam ${ }^{\mathrm{CKO} / \mathrm{KO} O}$ mouse. Knowing that behaviors rely on precisely balanced inputs from excitatory and inhibitory neurons, both of which express PAM (15), we bred

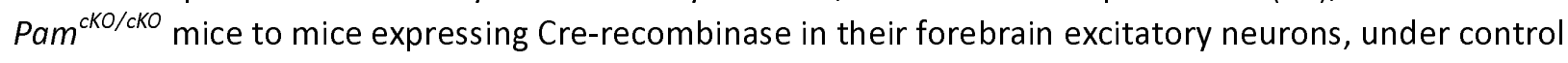
of the spiracles homeobox 1 promoter $(E m x-1 C r e)(16,17)$. Given the high levels of PAM expressed in 
atrial cardiomyocytes (18), we also bred $\mathrm{Pam}^{\mathrm{cKO} / \mathrm{CKO}}$ mice to mice expressing Cre-recombinase under control of the cardiac myosin heavy chain 6 promoter (Myh6-Cre) $(19,20)$. Tests of anxiety-like behavior and thermal regulation demonstrated alterations in both lines. Although atrial natriuretic peptide (ANP) is not amidated, ANP levels fell dramatically in Pam ${ }^{\text {Myh6-cKO/cKO }}$ mice and gene expression was altered.

Using the Pam ${ }^{\mathrm{cKO} / \mathrm{cKO}}$ mouse, PAM expression and amidated peptide levels can be altered in selected cell types when developmentally or experimentally expedient. In this way, it should be possible to identify the circuits and complex peptidergic pathways that play key roles behaviors of interest.

\section{$\underline{\text { METHODS }}$}

\section{Construction of the Pam ${ }^{\mathrm{cKO} / \mathrm{cKO}}$ mouse}

The Pam ${ }^{\mathrm{ckO} / \mathrm{ckO}}$ mouse was created directly on a C57BL6 background by Cyagen Biosciences (Santa Clara, CA), closely following the original Pam global (whole animal, not tissue- or cell-specific) knockout targeting Exons 2 and 3 on mouse Chromosome $1\left(\mathrm{Pam}^{\mathrm{KO} / \mathrm{KO}}\right)$ (11). The upstream loxP site is $300 \mathrm{nt}$ before the start of exon 2, bracketed by the Pam forward and reverse primers (Supplemental Table 1), and the downstream loxP site is $600 \mathrm{nt}$ beyond the end of Exon 3 (Supplemental Fig.1A). The Pam deletion primer is $2.7 \mathrm{~kb}$ from the Pam forward primer on the mouse genome, so the intervening DNA has to be removed for the outside primers to make the $310 \mathrm{nt}$ product in the 1 min polymerase chain reaction (PCR) elongation step. The three primer reaction makes possible genotyping distinguishing wildtype (WT), Pam ${ }^{\mathrm{cKO} /+}$ and $\mathrm{Pam}^{\mathrm{cKO} / \mathrm{cKO}}$ mice in one reaction, using DNA from identification earpunches. Tissue-specific verification of the excision of Exons $2+3$ was also demonstrated with the same primers and PCR program: 94C, 3m; 94C, 30s; 60C, 35s; 72C, 1m; 32 cycles. The $\mathrm{Pam}^{\mathrm{cKO} /+}$ and $\mathrm{Pam}^{\mathrm{cKO} / \mathrm{cKO}}$ mice were born in the expected Mendelian ratios, were fertile and exhibited no obvious abnormalities (see below).

\section{Mice expressing Cre-recombinase}

Two lines of Cre-recombinase mice were purchased from Jackson Laboratories (Bar Harbor, ME).

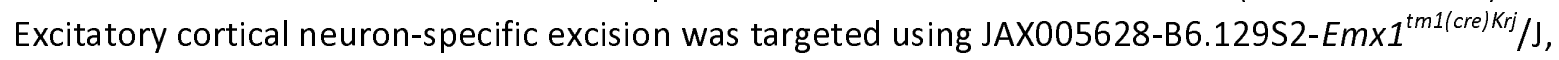
maintained on a C57BL/6J background as homozygotes (16). Convenient genotyping required sequencing the 3'UTR of the Emx1 gene in the Emx1-Cre mice, to make possible three-primer screening (Supplemental Fig.1B; Suppl.Table 1). Three primer reactions distinguished WT, heterozygous and homozygous Emx1-Cre mice (94C, 3m; 94C, 30s; 61C, 30s; 72C,1m; 30 cycles). As noted on the JAX website, germline expression of Cre recombinase occurred at a low but significant frequency in mice expressing Emx1-Cre and one floxed PAM allele. Evidence of this conversion was observed in ear punches and tail clips as well as verified with multiple brain and heart tissues genotyped using the $\mathrm{Pam}^{\mathrm{cKO}}$ primer set. The mice with Pam recombination of a single allele in all tissues were similar to the previously studied $\mathrm{Pam}^{\mathrm{KO} /+}$ global heterozygote knockout mice $(11,14,21)$ in every tested biochemical, physiological and behavioral parameter. These $\mathrm{Pam}^{\mathrm{KO} /+}$ mice were thus excluded from the current analyses. Excitatory neuron-specific PAM knockout mice were produced with Emx1-Cre expressed in one or both parents, since there was no evidence of any problems with Emx1-Cre homozygosity. Excitatory neuron-specific Pam knockouts are designated Pam ${ }^{\mathrm{Em} \times 1-\mathrm{cKO} / \mathrm{cKO}}$ and heterozygotes are Pam $^{\mathrm{Em} \times 1-\mathrm{cKO} /+}$.

Cardiomyocyte-specific expression of Cre-recombinase was achieved using JAX011038-B6.FVB-Tg(Myh6cre)2182Mds/J, maintained on a C57BL/6J background as hemizygotes (19). Genotyping was performed 
with a primer set closely modeled on the primers suggested on the JAX website (Supplemental Fig.1C;

Suppl.Table 1); the primers were modified to enable the use of three primers in a single definitive genotyping for each animal (94C, 3m; 94C, 30s; 62C, 30s; 72C,45s; 30 cycles). As suggested on the JAX website, cardiomyocyte-specific Pam knockout mice (Pam ${ }^{\mathrm{Myh6}-\mathrm{cKO} / \mathrm{cKO}}$ ) were produced with Myh6-Cre expressed in only one parent, to avoid the potential toxicity of Myh6-Cre homozygosity. Cardiac-specific Pam knockouts are designated Pam ${ }^{\mathrm{Myh6-ckO/cKO}}$ and heterozygotes are Pam ${ }^{\mathrm{Myh6-cKO/+}}$. Heart weight was unaltered in adult Pam ${ }^{\text {Myh6-cKo/ckO }}$ mice.

\section{Biochemical analyses}

Lysates for PHM and PAL assays were prepared by homogenizing tissue in $20 \mathrm{mM}$ Na TES, $10 \mathrm{mM}$ mannitol, 1\% TX-100, pH 7.4 (TMT), with protease inhibitors; all manipulations were carried out on ice, as described (22). Lysates for SDS-PAGE were prepared using SDS-P buffer with protease inhibitor cocktail; after boiling and sonication, particulate material was removed (23). Lysates were also prepared by sonication into ice cold RIPA Buffer (Cell Signaling Technologies, Danvers, MA; \#9806) containing protease inhibitors (Sigma P8340, MilliporeSigma, Burlington MA); particulate material was then removed. Protein concentrations were determined using the bicinchoninic acid assay (Thermo Fisher, Waltham MA), with bovine serum album in as the standard. For PHM and PAL activity assays, samples were diluted to $0.1 \mathrm{mg} / \mathrm{ml}$ and assayed in triplicate. Amounts and assay times were adjusted to ensure assay linearity: atrium $(0.2 \mu \mathrm{g}, 30 \mathrm{~min})$, ventricle $(1.0 \mu \mathrm{g}, 120 \mathrm{~min})$, cortex (5.0 $\mu \mathrm{g}, 60 \mathrm{~min})$, hypothalamus ( $2.0 \mu \mathrm{g}, 60 \mathrm{~min})$, olfactory bulb (1.0 $\mu \mathrm{g}, 60 \mathrm{~min})$.

For Western blots, samples were denatured in SDS sample buffer by heating at $95^{\circ} \mathrm{C}$ for $5 \mathrm{~min}$ : for atrium, 5 or $10 \mu \mathrm{g}$ of protein was loaded; for all other tissues, 10 or $20 \mu \mathrm{g}$ of protein was loaded (22). Samples fractionated on Bio-Rad Criterion TGX Precast 4-15\% gradient gels were transferred to Immobilon-P transfer membranes (Millipore). Membranes were blocked with 5\% milk in TTBS before overnight incubation with primary antibody and visualization using HRP-tagged secondary antibody (Jackson ImmunoResearch Laboratories, West Grove, PA) and SuperSignal West Pico PLUS Chemiluminescent substrate (ThermoFisher). ProANP was detected using rabbit polyclonal antibody to proANP(1-16) (kindly provided by Dr. Christopher Glembotski, San Diego State University) (24, 25); ANP was detected with a goat antibody (ab190001, Abcam, Cambridge MA). PAM was visualized using affinity-purified rabbit polyclonal antibodies to the linker region separating PHM from PAL in PAM-1 (JH629; RRID:AB_2721274) (22), and to the extreme cytoplasmic domain of PAM (C-Stop: RRID:AB_2801640) (26). In addition to using Coomassie Brilliant Blue staining to verify equal loading, Iqgap was visualized using a mouse monoclonal antibody (\#610611, BD Transduction Laboratories, San Jose, CA). Western blot signals in the linear range were densitized using GeneTools software (Syngene, Frederick MD).

The ELISA for ANP was performed as described (EIAM-ANP-1, RayBiotech, Peachtree Corners, GA), except that the standard curve was modified to include 4-fold dilutions from $80 \mathrm{pg}$ to $0.0195 \mathrm{pg}$; values were calculated using a logit-log transformation. Tissue and serum samples were prepared as described by de Bold, Smithies and coworkers $(27,28)$ using UltraMicroSpin C18 silica columns (Nest Group, Southborough, MA). Serum renin levels were determined using an ELISA kit (ELM-Renin1-1, RayBiotech).

\section{Tissue and cellular specificity of PAM ablation}


As an initial determination of the sites of PAM depletion, Myh6-Cre and Emx1-Cre mice were individually crossed with TdTomato reporter mice, and $\mathrm{Pam}^{\mathrm{Em} \times 1-\mathrm{cKO} / \mathrm{cKO}}$ mice were studied directly (29). Direct observation of PAM at the cellular level was accomplished by immunocytochemistry as described (30) using affinity-purified PAM polyclonal antibody JH629. Nuclei were visualized with Hoechst stain and, where indicated, Gad67 was visualized using a mouse monoclonal antibody (clone 1G10.2, Millipore) (31). Confocal imaging was performed on $12 \mu \mathrm{m}$ sections with a Zeiss LSM 880 microscope with a 20x, $40 x$, or $63 x$ objective; where indicated, z-stacks were taken and a single image is shown.

\section{Behavioral and physiological analyses}

All experiments were performed in the same circadian period (0900-1600). Mice were handled by the same animal tester for 60 seconds a day for two days before determining the fraction of time in the open area of the elevated zero maze (San Diego Instruments, San Diego, CA) (32). Mice were video recorded once for $5 \mathrm{~min}$; times were obtained by watching the movies. Next, the general mobility and motor coordination of the mice were tested using the open field and rotarod (29, 32). Rotarod testing was performed three times a day for 3 days, using a Five Lane Rota-Rod for Mouse (Med Associates, Georgia, VT). Each trial lasted no longer than $5 \mathrm{~min}$, with the speed increasing from $4 \mathrm{rpm}$ to $40 \mathrm{rpm}$. The longest time recorded for each day was used in the analysis. Open field ambulations were recorded for 15-45 min (see Figure Legends) in a Photobeam Activity System Open Field (San Diego Instruments). When the locomotor response to cocaine was tested, cocaine was administered by intraperitoneal injection and open field ambulations were recorded for $45 \mathrm{~min}$ on successive days or after a brief withdrawal period; cocaine injections were $10 \mathrm{mg} / \mathrm{kg}$ except for day 2, which was $20 \mathrm{mg} / \mathrm{kg}(33,34)$.

Core body temperature was recorded over a 3-hour period using a rectal thermometer (14).

Temperature readings were collected before entering the $4^{\circ} \mathrm{C}$ cold room and once each following hour in the cold room. During the $3 \mathrm{~h}$ experiment, mice were singly housed in plain pre-chilled mouse cages with no bedding, food or water. Abdominal and tail temperatures during 20 min restraint in an unfamiliar environment (ventilated $50 \mathrm{ml}$ tube) at room temperature were determined using a Hti Dual Laser Infrared Thermometer $(35,36)$. Blood pressure was determined using the tail cuff method (CODA Multi Channel, Computerized, Non-Invasive Blood Pressure System for Mice and Rats; Kent Scientific Corporation, Torrington, CT) $(28,37,38)$; arterial blood pressures by tail cuff method or telemetry are identical with experienced operators (37). Dietary $\mathrm{NaCl}$ was varied using standard mouse chows from Envigo (Huntingdon, UK): diet TD.96208 contained 0.49\% NaCl; the high salt diet TD.92012 contained 8\% $\mathrm{NaCl}$. The standard chow in the University of Connecticut Health Center Animal Tower was the irradiated version of the Teklad Global 18\% Rodent Diet (2918) from Envigo and contained $0.49 \% \mathrm{NaCl}$, which we refer to as a normal salt diet. The effect of elimination of sympathetic nervous system input on systemic blood pressure was determined $10 \mathrm{~min}$ after intraperitoneal injection of $0.9 \%$ saline (control) or hexamethonium (30 mg/kg) (\# 4111, Tocris, Minneapolis, MN) in saline $(38,39$ ).

For behavioral testing, control animals (CON) included wildtype mice and mice with one or two floxed Pam alleles but no Cre-recombinase, or Cre-recombinase but no floxed Pam alleles, since these mice were behaviorally and biochemically indistinguishable from wildtype mice. Only wildtype mice were used as controls in physiological testing (e.g. blood pressure). Since males and females did not differ within a genotype except for body weight and blood pressure values, data were pooled across sexes for each genotype. 


\section{RNA-Sequencing}

RNA prepared from individual adult mouse atria was sequenced and aligned as described $(10,34)$. Sequencing was paired-end with 4.7 to 7.4 million reads mapped to $\mathrm{mm} 10$ per sample. Differential expression was analyzed using DESeq2 analyses $(40,41)$ (https://bioconductor.org/packages/release/bioc/html/DESeq2.html) (cutoff $p<0.05$ ), followed by removal of outliers (10,34). RNASeq data were analyzed using Ingenuity Pathway Analysis (Qiagen, Germantown, MD) (10, 34). Sequencing data are available online (GEO Submission GSE132180).

\section{Data and Unique Materials Availability}

All data, protocols and reagents (e.g. antisera) are available upon request to eipper@uchc.edu or mains@uchc.edu. The Pam ${ }^{\mathrm{ckO} / \mathrm{ckO}}$ mice are available on request by qualified researchers for their own use. These mice will be deposited at JAX as soon as possible.

\section{Statistical analyses}

Student t-tests were applied in pairwise comparisons of enzyme activity or protein abundance (Excel or OpenOffice). Time courses (e.g. growth curves) were subjected to 2-way ANOVA (Prism 8). RNAseq differential expression was evaluated using DESeq2, which has its own built-in statistical comparisons.

\section{RESULTS}

\section{Mice lacking Pam expression driven by Emx1-Cre or Myh6-Cre grow and perform locomotor tasks normally}

PAM activity is detected in mouse embryos by embryonic day 12.5 (E12.5); embryos unable to express Pam are not found after E14.5 (11). Since Emx1-Cre is active by E10.5 (16) and an Myh6-LacZ reporter is expressed in the E9.5 atrium (20), it is likely that Cre-recombinase mediated excision of Pam exons 2 and 3 occurs before expression of Pam would have begun. In the tissues and sera of adult heterozygous global Pam knockout mice $\left(\mathrm{Pam}^{\mathrm{KO} /+}\right)$, PAM activity and protein levels are approximately half of wildtype values (11).

For both tissue-specific Pam ${ }^{\mathrm{cKO} / \mathrm{ckO}}$ lines, females grew normally from weaning to 100 days of age

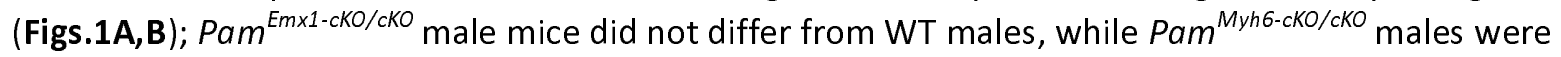
slightly larger than WT $\left[\mathrm{p}<0.0001,2\right.$-way ANOVA]. When Pam ${ }^{\mathrm{Em} \times 1-\mathrm{cKO} /+}$ mice were mated with Pam $\mathrm{cKO} /+^{-}$ mice, the genotypes of progeny tested at weaning occurred in the expected Mendelian ratio ( $\mathrm{N}=226$; N.S. by 2-way ANOVA) (Supplemental Fig.2A). Similarly, when Myh6-Cre progeny were tested, the expected Mendelian ratio of genotypes was observed ( $N=198$; N.S. by 2-way ANOVA) (Supplemental Fig.2B).

Since most behavioral tests require normal mobility, we tested male and female Pam $^{\text {Em×1-cko/cko }}$ and $\mathrm{Pam}^{\mathrm{Myh} 6-\mathrm{ckO} / \mathrm{cKO}}$ mice on the Rotarod and in the Open Field. Since no differences were observed in the behavior of wildtype, $\mathrm{Pam}^{\mathrm{cKO} / \mathrm{cKO}}, \mathrm{Pam}^{\mathrm{cKO} /+}$ and Emx1-Cre or Myh6-Cre mice, all were used as controls (CON). The Pam ${ }^{\mathrm{Em} \times 1-\mathrm{cKO} / \mathrm{ckO}}$ and Pam ${ }^{\mathrm{Myh6} 6 \mathrm{-kO} / \mathrm{ckO}}$ mice were as active as control mice in the Open Field (Fig.1C); no differences were observed in the performance of male and female mice. Male and female $\mathrm{Pam}^{\mathrm{Em} \times 1-\mathrm{cKO} / \mathrm{cKO}}$ and Pam ${ }^{\mathrm{Myh} 6-\mathrm{cKO} / \mathrm{cKO}}$ mice performed as well as control mice on the Rotarod (Fig.1D); no differences were observed between male and female mice. 


\section{Pam knockout is tissue-specific and effective}

We used assays for PHM and PAL enzyme activity to assess the success of our knockout strategies. In order to extract both soluble and membrane forms of PAM, tissue from adult male and female mice was homogenized in lysis buffer containing 1\% TX-100; similar results were obtained using both assays (Figs.2A,B). PHM and PAL specific activities were reduced to $25 \%$ of wildtype values in cortical and olfactory bulb lysates prepared from $\mathrm{Pam}^{\mathrm{Em} \times 1-\mathrm{cKO} / \mathrm{cKO}}$ mice. A less extreme reduction in PHM and PAL specific activities was also observed in hypothalamic lysates prepared from Pam ${ }^{\text {Emx1-ckO/ckO }}$ mice. PHM and PAL specific activities were reduced to $2 \%$ of wildtype values in the atria of Pam ${ }^{\mathrm{Myh} 6-\mathrm{ckO} / \mathrm{cKO}}$ mice. PHM and PAL specific activities, which are much lower in the adult ventricle, were reduced to $25 \%$ of wildtype values in Pam ${ }^{\mathrm{Myh6}-\mathrm{cKO} / \mathrm{cKO}}$ mice. In contrast, the specific activities of both enzymes in the atria and ventricles of $\mathrm{Pam}^{\text {Emx1-cko/cko }}$ mice were equal to wildtype values, and PHM and PAL specific activities in lysates prepared from the sensory-motor cortices of Pam ${ }^{\mathrm{Myh} 6-\mathrm{cKO} / \mathrm{cKO}}$ mice did not differ from wildtype values.

Finally, Western blot analyses of lysates prepared from Pam ${ }^{\text {Emx1-cko/cko }}$ and Pam ${ }^{\text {Myh6-cko/cko }}$ mice confirmed the enzyme assay results. In the atrium, intact PAM (110 kDa) was the major product, with smaller amounts of soluble PHM (40 kDa) (Fig.2C,E). In both cortex and hypothalamus, soluble PHM was the major product and levels were unaltered in $\mathrm{Pam}^{\mathrm{Myh6}-\mathrm{ckO} / \mathrm{ckO}}$ mice. In contrast, in the cortex and hypothalamus of Pam ${ }^{\mathrm{Em} \times 1-\mathrm{cKO} / \mathrm{cKO}}$ mice, levels of both intact PAM and soluble PHM were reduced compared to wildtype levels (Fig.2D,E). PAM protein levels were unaltered in the atria and ventricles of $\mathrm{Pam}^{\mathrm{Em} \times 1-\mathrm{cKO} / \mathrm{cKO}}$ mice.

Anxiety-like behavior, locomotor response to cocaine and thermoregulation are altered in Pam ${ }^{\text {Emx1- }}$ cko/cko mice

Based on the extensive literature on peptidergic signaling in the nervous system and the phenotypes observed in $\mathrm{Pam}^{\mathrm{KO} /+}$ mice, we first examined Pam ${ }^{\mathrm{Em} \times 1-\mathrm{cKO} / \mathrm{cKO}}$ mice. Previously, Pam ${ }^{\mathrm{KO} /+}$ mice exhibited a striking increase in anxiety-like behavior compared to wildtype mice $(14,42)$; this increase was largely ameliorated when the mice were fed a copper supplemented diet. Anxiety-like behavior was tested using the elevated zero maze (Fig.3A). Unlike mice with a single allele of Pam in all of their tissues (Fig.3A, red arrow), Pam ${ }^{\mathrm{Em} \times 1-\mathrm{ckO} / \mathrm{ckO}}$ mice showed an increase in time spent in the open arms of the maze, a response interpreted as a decrease in anxiety-like behavior. Anxiety-like behavior in Pam ${ }^{\mathrm{Em} \times 1-\mathrm{ckO} /+}$ mice, with a single copy of Pam only in Emx1-positive cells, did not differ from control mice (Fig.3A).

Studies from many laboratories have revealed a role for amidated peptides in cocaine selfadministration and cocaine-seeking behavior during withdrawal (43-48). Neuropeptide Y (NPY), oxytocin and the hypocretins (also called orexins) modulate these behaviors and are inactive if not amidated. We tested the response of $\mathrm{Pam}^{\mathrm{Em} \times 1-\mathrm{cKO} / \mathrm{cKO}}$ mice to four injections of cocaine, four days of abstinence and a final injection of cocaine (Fig.3B) (34). No difference was observed in the response of wildtype and Pam ${ }^{\mathrm{Em} \times 1-\mathrm{cKO} / \mathrm{cKO}}$ mice to the initial administration of saline (Day 1). Pam ${ }^{\mathrm{Em} \times 1 \text {-ckO/cKO }}$ mice exhibited a much greater response to the initial high dose of cocaine than wildtype mice (Day 2); this increased responsiveness was maintained throughout the entire experimental protocol (RM-ANOVA, $\mathrm{p}<0.0001)$.

Thermoregulation was studied because the diminished ability of $\mathrm{Pam}^{\mathrm{KO} /+}$ mice to vasoconstrict peripheral blood vessels led to a marked inability to maintain core body temperature when kept at $4 \mathrm{C}$ 
(14); this deficit forced termination of the previous experiments after $2 \mathrm{~h}$ in the cold, when body temperature in Pam ${ }^{\mathrm{KO} /+}$ mice fell to $34 \mathrm{C}$ (Fig.3C, red arrow). Pam ${ }^{\mathrm{Em} \times 1-\mathrm{cKO} / \mathrm{KO}}$ mice outperformed control mice when maintained in a $4 \mathrm{C}$ environment for a prolonged period of time (Fig. $3 \mathrm{C}$ ). In WT mice, body temperature fell significantly between 2 and $3 \mathrm{~h}$ of cold exposure; Pam ${ }^{\mathrm{Em} \times 1-\mathrm{cKO} / \mathrm{cKO}}$ mice were better able to maintain core body temperature for $3 \mathrm{~h}$ in a $4 \mathrm{C}$ environment (Fig.3C). Since PAM expression is reduced to half in both excitatory and inhibitory neurons in $\mathrm{Pam}^{\mathrm{KO} /+}$ mice while $\mathrm{Pam}^{\mathrm{Em} \times 1-\mathrm{cKO} / \mathrm{cKO}}$ mice lack PAM expression only in excitatory neurons, a difference in their ability to maintain core body temperature was anticipated. Excitatory neurons in the median preoptic area of the hypothalamus promote peripheral dilatation and core heat loss, and produce a number of amidated peptides which strongly affect thermoregulation $(49,50)$.

\section{Excitatory neurons in the hippocampus and cortex of $\mathrm{Pam}^{\mathrm{Em} \times 1-\mathrm{cKO} / \mathrm{cKO}}$ mice lack PAM}

We used a reporter line in which a fluorescent marker, TdTomato, is produced in cells expressing Crerecombinase to verify the specificity of our knockout strategy at the cellular level (29). To evaluate the overlap between TdTomato-positive cells and PAM-positive cells, PAM was visualized using an antiserum specific for PAM-1 (Fig.4); immunocytochemistry controls are presented in Supplemental

Figs.3-6. As expected (15), TdTomato expression was observed in pyramidal neurons in the CA1 and CA3 regions of the hippocampus in Emx1 Cre-recombinase mice (Fig.4A,B,C, yellow arrows). Since the TdTomato reporter is cytosolic, the axons and dendrites of TdTomato-expressing neurons were fluorescent. This was especially apparent in the CA3 region, where a significant fraction of the granule cell mossy fiber endings ( $\mathrm{mf}$ ) innervating the dendrites of the CA3 pyramidal neurons were bright red (Fig.4C, mf).

Consistent with our previous in situ hybridization study (15), the vast majority of pyramidal neurons (Pyr) in both the CA1 and CA3 regions of the hippocampus expressed PAM (AlexaFluor488; green)

(Fig.4B,C, yellow arrows); PAM staining was also strong in the mossy fibers. Large, strongly PAM-positive neurons that were not TdTomato-positive were scattered throughout the pyramidal cell layer in CA1 and CA3 and in the stratum oriens and stratum lacunosum-moleculare (Fig.4B,C, green arrows).

In Layer 2 of the cerebral cortex (Fig.4D), all of the TdTomato-expressing neurons (red) were PAMpositive (yellow arrows), suggesting that most of the excitatory neurons in cortical layer 2 could utilize amidated peptides for signaling. PAM-staining in the TdTomato-positive pyramidal projection neurons in cortical layer 5 was less intense, but all of the TdTomato-positive neurons expressed PAM (Fig.4E, yellow arrows). The layer 5 neurons with the most intense PAM signal were not TdTomato-positive, suggesting that they were interneurons (Fig.4E, green arrows).

The number of neurons in layers 2 and 5 expressing TdTomato and stained for PAM and the number of PAM-positive neurons not expressing TdTomato was compared to the total number of nuclei (Fig.4F). In both layers, the number of neurons expressing PAM, but not expressing TdTomato was approximately one fifth of the number of neurons expressing both PAM and TdTomato.

\section{PAM is highly expressed in GAD67-positive interneurons}

Given the importance of excitatory/inhibitory balance in nervous system function, we wanted to identify PAM-positive inhibitory neurons; to do so, coronal sections from control and Pam ${ }^{\mathrm{Em} \times 1 \text {-ckO/cKO }}$ mice were stained simultaneously for PAM (green) and glutamic acid decarboxylase 67 (GAD67) (red) (Fig.5). The strongly PAM-positive neurons seen in the stratum oriens and stratum lacunosum moleculare of the CA3 region in both control and Pam ${ }^{\mathrm{Em} \times 1-\mathrm{cKO} / \mathrm{cKO}}$ mice were largely GAD-positive (Fig.5A, yellow arrows). 
Strikingly, the PAM-positive mossy fibers observed in the wildtype CA3 region were not seen in the

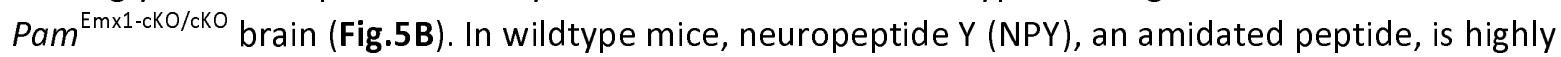
expressed in mossy fibers (30). The diffuse nature of the AlexaFluor488 signal observed in pyramidal neurons in the Pam ${ }^{\text {Emx1-cko/ckO }}$ mice (Fig.5B) resembled the background observed when PAM antibody was replaced by non-immune rabbit immunoglobulin or blocked with antigenic peptide (Suppl.Figs.4-7).

In cortical layer 2 (Fig.5C, D), very few PAM-positive neurons were identified in Pam ${ }^{\text {Emx1-cKo/cko }}$ mice; almost all of the remaining PAM-positive neurons expressed GAD67 (inhibitory neurons) (Fig.5D, yellow

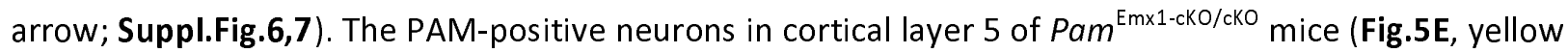
arrow), were almost always GAD67-positive (inhibitory) (Suppl.Fig.6,7). In the cerebral cortices of WT mice, there were PAM-positive neurons not positive for GAD, as expected from the majority of PAMpositive neurons that were Emx1-positive (Fig.4) (white arrows). In addition, in Pam ${ }^{\text {Emx1-cko/cKO }}$ mice, there were PAM-positive neurons that were not GAD-positive (Fig.5E, white arrows). The decreases in PAM-positive neuron numbers in cortical layers 2 and 5 in Pam ${ }^{\mathrm{Em} \times 1-\mathrm{cKO} / \mathrm{cKO}}$ mice (L2: 56\%; L5: 39\%) closely matched the number of neurons expressing both PAM and TdTomato in the Emx1-Cre reporter mice (L2: $56.0 \pm 9.5 \%$; L5: $44.3 \pm 6.4 \%$ ) (summarized in Supplemental Table 2).

\section{Anxiety-like behavior and thermoregulation are altered in Pam ${ }^{\text {Myh6-cKo/cKo }}$ mice}

Although atrial levels of PAM are at least 10-fold higher than cortical levels (18) (Fig.2), neither proANP nor pro-brain natriuretic peptide (pro-BNP) is amidated. The tests used to characterize Pam ${ }^{\text {Emx1-cko/cko }}$ mice (Fig.3) were also used to evaluate Pam ${ }^{\text {Myh6-cko/cko }}$ mice (Fig.6). When tested for anxiety-like behavior, the Pam ${ }^{\mathrm{Myh} 6-\mathrm{ckO} / \mathrm{ckO}}$ mice responded in much the same way as $\mathrm{Pam}^{\mathrm{KO} /+}$ mice; time spent in the open arms decreased to about half of the value observed in control mice (Fig.6A). The anxiety-like behavior of $\mathrm{Pam}^{\mathrm{Myh} 6-\mathrm{cKO} /+}$ mice did not differ from that of control mice. When tested using the cocaine injection paradigm described in Fig.3B, Pam ${ }^{\text {Myh6-cko/ckO }}$ mice showed an enhanced response only on Day 2 $(\mathrm{p}<0.02)$; unlike Pam $^{\mathrm{Em} \times 1-\mathrm{ckO} / \mathrm{ckO}}$ mice, the elevated response was not sustained (Fig.6B). Like Pam ${ }^{\text {Emx1- }}$ ${ }_{\mathrm{cKO} / \mathrm{ckO}}$ mice, $\mathrm{Pam}^{\mathrm{Myh} 6-\mathrm{ckO} / \mathrm{ckO}}$ mice were better able than wildtype mice to maintain core body temperature for $3 \mathrm{~h}$ in a $4 \mathrm{C}$ environment (Fig.6C).

The marked improvement in the ability of the $\mathrm{Pam}^{\mathrm{Myh} 6-\mathrm{ckO} / \mathrm{ckO}}$ mice to maintain core body temperature for $3 \mathrm{~h}$ suggested that these mice had an enhanced coping mechanism whereby they could redirect peripheral blood flow to the core $(35,36)$. A common test for this ability is use of a heat-sensitive probe to monitor tail temperature while the animal is kept in an unaccustomed restraint device for $20 \mathrm{~min}$ (35, 36); abdominal temperature is measured with the same probe before and after the 20 min restraint, and the temperature differential (abdomen minus tail) is reported (Fig.6D). Measured in this manner, abdominal temperature was the same in $\mathrm{Pam}^{\mathrm{Myh6-cko/ckO}}$ and WT mice both before and after restraint. The tail temperature differential was significantly greater in Pam ${ }^{\mathrm{Mhh6}-\mathrm{cKO} / \mathrm{cKO}}$ mice than in WT mice after 20 min of restraint, indicating an enhanced ability of $\mathrm{Pam}^{\mathrm{Myh6-ckO/cKO}}$ mice to constrict tail blood flow.

\section{Atrial levels of pro-atrial natriuretic peptide (proANP) decline in Pam ${ }^{\mathrm{Myh6-cKO} / \mathrm{KO}}$ mice}

As expected from the literature $(19,20)$ and consistent with the dramatically reduced levels of PAM

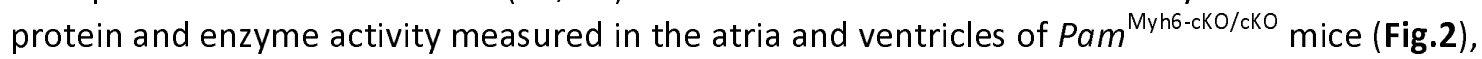
TdTomato was uniformly expressed in atrial and ventricular cardiomyocytes when driven by the Myh6 promoter (Suppl.Fig.7).

PAM is the major protein in the membranes of atrial secretory granules, which store proANP and proBNP $(7,51-53)$. PAM interacts directly with proANP, which is not cleaved until the time of secretion 
$(25,54)$. Lysates prepared from WT and Pam ${ }^{\mathrm{Myh6}-\mathrm{ckO} / \mathrm{ckO}}$ atria using $1 \%$ deoxycholate to ensure better protein solubilization were subjected to western blot analysis (Fig.7A). As assessed using antibodies to PAM Exon 16 (JH629) and to the cytoplasmic domain of PAM (C-Stop), PAM levels in Pam ${ }^{\text {Myh6-cko/ckO }}$ atria were negligible. ANP levels were assessed using an antibody specific for the $\mathrm{N}$-terminal region of proANP and an antibody specific for a 15-residue peptide contained within mature ANP, a 28-residue

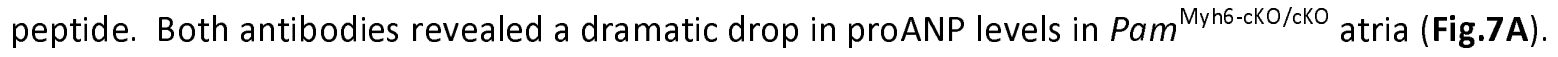

To determine whether the decline in proANP levels in the atria of Pam ${ }^{\text {Myh6-cko/cko }}$ mice was accompanied by altered circulating levels of ANP, we utilized an ELISA to quantify atrial and serum levels of ANP in $\mathrm{Pam}^{\mathrm{MyhG}-\mathrm{ckO} / \mathrm{cKO}}$ and WT mice (Fig.7B). Levels of ANP in the atria and sera of Pam ${ }^{\mathrm{Myh6}-\mathrm{ckO} / \mathrm{ckO}}$ mice were dramatically lower than in control mice. Although PAM expression in the atrium exceeds levels in any other tissue examined, levels of serum PHM activity were unaltered in Pam ${ }^{\text {Myh6-cko/ckO }}$ mice (Fig.7C), eliminating the atrium as a major source of serum PAM.

\section{Blood pressure regulation is altered in Pam $^{\mathrm{Myh6-ckO/cko}}$ mice}

ANP has been referred to as a natural antihypertensive agent (55); along with several other peptides, ANP participates in the control of blood pressure and the ability of mammals to respond to changes in dietary salinity and cardiovascular fluid volume $(38,56-58)$. Since circulating levels of ANP were undetectable in Pam ${ }^{\mathrm{Myh} 6-\mathrm{ckO} / \mathrm{ckO}}$ mice, their ability to regulate blood pressure in response to a change in dietary salt load was examined. When fed a normal salt diet $(0.49 \% \mathrm{NaCl})$ for two months, no

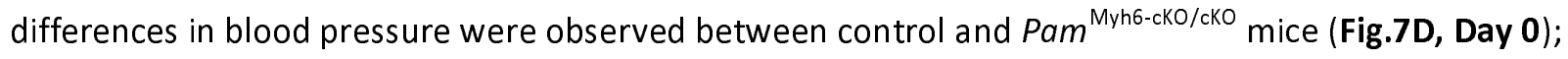
blood pressure was consistently slightly higher in female mice than in male mice, irrespective of PAM genotype.

This result suggested that other systems might be compensating for the low levels of ANP in Pam ${ }^{\text {Myh6- }}$ $\mathrm{ckO} / \mathrm{ckO}$ mice. The renin-angiotensin system increases blood pressure by stimulating the conversion of angiotensinogen to angiotensin I; renin secretion is stimulated by low blood sodium and sympathetic input, and suppressed by ANP (59). However, assays for serum renin levels in WT and Pam ${ }^{\text {Myh6-cko/ckO }}$ mice on a normal salt diet revealed no difference (Fig.7E).

The WT and Pam ${ }^{\mathrm{Myh6}-\mathrm{ckO} / \mathrm{ckO}}$ mice, whose blood pressure was monitored after two months on a normal salt diet, were fed a high salt diet (8\% NaCl) for a week (Fig.7D; days 4-10). No changes in blood pressure

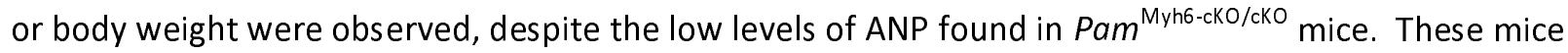
were then returned to the normal salt diet (days 11-18), again with no changes observed in blood pressure.

The sympathetic system, a major ANP target $(38,60)$, plays an essential role in blood pressure control. Hexamethonium, a ganglionic blocker that eliminates all presynaptic sympathetic ganglion input, was

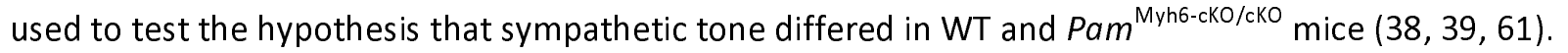
As expected, control mice exhibited an approximately $20 \mathrm{~mm} \mathrm{Hg}$ decrease in arterial blood pressure 10 min after an injection of hexamethonium (Fig.7F). In contrast, blood pressure in Pam ${ }^{\text {Myh6-cko/cKO }}$ mice was unaltered after hexamethonium injection, revealing a striking absence of sympathetic tone.

\section{The transcriptome is altered in Pam ${ }^{\mathrm{Myh} 6-\mathrm{ckO} / \mathrm{ckO}}$ atrium}

The homogeneity of atrial tissue, lack of a major amidated product despite high levels of Pam expression and changes observed in the Pam ${ }^{\mathrm{Myh} 6-\mathrm{ckO} / \mathrm{ckO}}$ mice led us to ask whether changes in gene expression might contribute to the phenotypes observed. Alterations in the atrial transcriptome could reflect the 
inability of these cells to produce $\operatorname{sfCD}$ (soluble fragment of the PAM cytosolic domain, which translocates to the nucleus) (26), a direct response to the diminished levels of ANP or compensatory responses by the many systems involved in regulating these fundamental processes. Atrial RNA was prepared from WT and Pam ${ }^{\mathrm{Myh6}-\mathrm{cKO} / \mathrm{ckO}}$ mice and sequenced (Fig.8A; Suppl.Table3).

DESeq2 analysis of differential expression was performed on the counts data, yielding 1063 transcripts with $\mathrm{p}<0.05$; when outliers were eliminated (34), the number of differentially expressed transcripts dropped to 555 . When depicted as a volcano plot, the vast majority of over 14,000 transcripts with average FPKM $>1$ were clustered near the origin, with a WT/KO ratio within the $0.5-2.0$ range (Log2 [ratio] -1 to +1 ) and a DESeq2 $p$ value $>0.05$.

The 555 significantly altered transcripts were subjected to Ingenuity Pathway Analysis (IPA) (Fig.8B,C; Suppl.Fig.8) (34). One of the most significantly regulated networks identified by IPA was the Apelin network. Apelin (Gene ID 8862) is an adipokine made in the atrium whose FPKM level rose 2.6-fold in $\mathrm{Pam}^{\mathrm{Myh} 6-\mathrm{ckO} / \mathrm{cKO}}$ mice compared to WT. Apelin is used clinically to treat insulin resistance and hypertension (62). Another major network includes a set of transcripts involved in circadian rhythms (three Period genes, Clock, Bhlhe40 and Arntl). Bhlhe40 is a basic-helix-loop-helix protein which binds to the promoter of Per1 to repress Clock/Arntl activation of Per1; Bhlhe40 levels vary directly with blood pressure in Clock knockout mice (63). Three more significantly regulated networks identified by IPA are depicted in Suppl.Fig.8. The tight interconnections of these five predicted networks are striking, with several transcripts appearing in two or three of the five networks: Apln, Apold1, Gadd45b, Bhlhe40, and Per1.

Many of the differentially expressed atrial transcripts were also identified as Pam-regulated genes in pituitary corticotrope cells (10). Strikingly, 20 of the 38 atrial transcripts in the five most significantly regulated networks responded to changes in Pam expression in the same manner in these two very different systems (marked with asterisks [*]). For example, expression of Per1 increased more than 2fold in Pam ${ }^{\mathrm{Myh} 6-\mathrm{cKO} / \mathrm{ckO}}$ mice compared to WT and decreased to $60 \%$ when Pam expression was increased in pituitary cells (10), suggesting that the change may be a direct response to altered PAM levels. Expression of 10 atrial transcripts (marked with ' $X$ ') decreased with loss of atrial PAM and also decreased in pituitary cells when PAM was increased (10), suggesting that these transcripts are not responding directly to the PAM protein but rather to some other compensatory changes or differences between the two tissues. Five of the 38 atrial transcript are not expressed at significant levels in pituitary cells (marked with ' 0 ').

\section{DISCUSSION}

Rationale: Peptidergic signaling in species as diverse as Trichoplax, Drosophila and human shares many common features (8). The preproproteins synthesized into the lumen of the ER undergo a series of post-translational modifications that generate a wide variety of products. In many cases these modifications are tissue-specific and generate multiple products that can interact with different receptors. The receptors, which are almost always $\mathrm{G}$ protein coupled receptors, may be located nearby or far away. Peptides play essential roles in the organism's response to nutrients and to noxious stimuli, function to distinguish self from non-self, participate in sexual reproduction, and control motility through their effects on ciliary beating and muscle contractility. Peptide expression is regulated at 
multiple levels, with changes in transcription, translation and post-translational processing as well as acute effects on peptide release. This complexity has made it difficult to utilize specific peptides in the development of therapeutics.

To test the utility of $\mathrm{Pam}^{\mathrm{cKO} / \mathrm{ckO}}$ mice in revealing functionally significant effects of peptidergic signaling, we selected two Cre drivers. Based on the widespread expression of PAM throughout the nervous system (Figs.4,5; (15)), we utilized the Emx1-Cre mouse. A proper balance of excitatory and inhibitory inputs is critical to the functioning of many circuits and we hypothesized that loss of PAM in excitatory neurons would disrupt this balance. Eliminating the expression of vasoactive intestinal polypeptide, an amidated peptide, in inhibitory interneurons in the auditory cortex, alters acoustic gain (64). In the feeding-satiety network, different sets of neurons, many producing amidated peptides, battle for dominance (65). The Myh6-Cre mouse was selected to gain insight into the roles played by PAM in atrial myocytes, which produce massive amounts of $\operatorname{PAM}(18,51,52)$, but are not known to produce amidated peptides (Fig.2). Atrial myocytes store intact proANP in secretory granules whose major membrane protein is PAM $(51,52)$.

Immunostaining readily identified PAM in every TdTomato-positive neuron (Fig.4). This observation is consistent with the four-fold drop in PHM and PAL activity observed in the cortices of the Pam ${ }^{\text {Emx1-ckO/ckO }}$ mice. A subset of the GABA-positive neurons expressed PAM; in general, PAM staining in GABAergic neurons was more intense than in other neurons. Mice entirely lacking the ability to express PAM did not survive beyond E14.5 (11), with massive edema accompanied by a poorly formed vasculature. Surprisingly, mice lacking the ability to express PAM only in their cardiomyocytes did not exhibit these defects. Pam ${ }^{\mathrm{Myh6-cKO/cKO}}$ mice grew normally, performed as well as WT mice on the RotaRod and in the Open Field, and outperformed wildtype mice in thermoregulation tests.

Anxiety-like behavior: The amygdala plays a crucial role in anxiety (66). Anxiety-like behavior increased in $\mathrm{Pam}^{\mathrm{KO} / \mathrm{t}}$ mice, with reduced levels of PAM expression in both excitatory and inhibitory neurons (14). In contrast, eliminating Pam expression only in excitatory neurons resulted in a decrease in anxiety-like behavior (Fig.3A). Treatment of $\mathrm{Pam}^{\mathrm{KO} /+}$ mice with diazepam, a GABA-A receptor agonist, normalized their anxiety-like behavior, suggesting that it resulted from limited inhibitory tone $(14,42)$. Ifenprodil, which blocks a subtype of excitatory glutamate receptors, has anxiolytic actions in wildtype mice (67). If the net effect of the amidated peptides expressed in excitatory neurons is to facilitate the actions of glutamate, eliminating their expression in $\mathrm{Pam}^{\mathrm{Em} \times 1-\mathrm{ckO} / \mathrm{ckO}}$ mice would be expected to reduce anxiety-like behavior (Fig.3A). The deficits observed in the Pam ${ }^{\mathrm{Em} \times 1-\mathrm{cKO} / \mathrm{cKO}}$ mice indicate that further study is warranted, despite the large number of neuropeptides and receptors involved, the complexity of the circuits and the lack of specific pharmacological blockers.

The increase in anxiety-like behavior observed in $\mathrm{Pam}^{\mathrm{KO} /+}$ mice was mimicked in the atrium-specific total knockout Pam $^{\mathrm{Myh6-ckO/cKO}}$ mice (Fig.6A). The reduction in circulating ANP in Pam ${ }^{\mathrm{Myh6}-\mathrm{ckO} / \mathrm{ckO}}$ mice may contribute to this phenotype. There is a well-recognized correlation between high anxiety and low circulating ANP levels in human cardiovascular patients (68); a subset of patients with low anxiety have high circulating levels of the N-terminal pro-ANP (69). It is striking that a number of transcripts which could adversely affect cardiac function were altered in Pam ${ }^{\mathrm{Myh6} 6-\mathrm{cKO} / \mathrm{cKO}}$ mice, potentially contributing to anxiety: increased Hdac4, promoting myocardial ischemia; increased Prkag2, lowering heart rate; increased Usp2, blunting mineralocorticoid responsiveness and decreasing retention of high salt; 
decreased Ano1 (a Ca ${ }^{++}$activated $\mathrm{Cl}^{-}$channel) and increased Cacna1a $\left(\mathrm{Ca}^{2+}\right.$ channel), both potentially increasing the strength of heart contraction.

Response to cocaine: The locomotor response to cocaine involves altered signaling in the nucleus accumbens, with established roles for dopamine, glutamate, and amidated neuropeptides such as NPY, oxytocin and the hypocretins (Hcrt) (70-72). Activation of the NPY Y1 receptor in the amygdala increases self-administration of psychostimulants such as cocaine, while activation of the NPY Y2 receptor inhibits self-administration $(43,48)$. Hcrt1 and Hcrt2 are amidated peptides derived from adjacent regions of the Hcrt precursor. The Hcrtr1 receptor binds Hcrt1 much better than Hcrt2 (44) and selective inhibitors of Hcrtr1 receptors are in clinical trials to treat cocaine addiction (44). Systemic delivery of oxytocin reduces cocaine self-administration (47) (also in clinical trials). The anti-addictive actions of oxytocin,

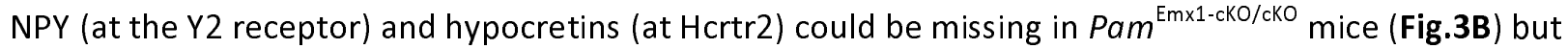
not in Pam ${ }^{\mathrm{Myh6}-\mathrm{ckO} / \mathrm{cKO}}$ mice (Fig.6B).

Thermoregulation: Pam ${ }^{\text {Emx1-cko/ckO }}$ mice withstand cold exposure better than wildtype mice (Fig.3C). The preoptic area of the hypothalamus is the central control region for core body temperature (50). Glutamatergic (excitatory, Emx1-expressing) neurons drive peripheral dilatation and severe hypothermia (49), while GABAergic neurons have less effect (73). Excitatory neurons in the preoptic area express many amidated neuropeptides: PACAP, CCK, CRH, oxytocin, tachykinin1 and GnRH (50, 74). Importantly, ablation of medial preoptic excitatory neurons causes dramatic hyperthermia $(49,75)$; deletion of PAM in these neurons (as for ablation) could produce peripheral vasoconstriction and core heat gain.

Pam $^{\mathrm{Myh6}-\mathrm{ckO} / \mathrm{ckO}}$ mice also withstand cold exposure better than wildtype mice (Fig.6C). The RNAseq results provide potential explanations for this, with markedly increased transcript levels of Gadd45g (Growth arrest and DNA-damage-inducible 45 gamma; also called Ddit2) and decreased Prkar2b (Protein kinase, CAMP dependent regulatory, type 2 beta). Both changes could increase the expression of uncoupling protein 1 (Ucp1), which is thermogenic, increasing metabolic rate. In addition, Pam ${ }^{\text {Myh6-cko/cko }}$ mice were more capable than wildtype mice of decreasing heat loss from the periphery (tail, limbs) under stress (restraint or coldroom) (Fig.6D).

Blood pressure: $P a m^{\mathrm{Myh} 6-\mathrm{cKO} / \mathrm{cKO}}$ mice showed no increase in blood pressure in response to salt loading (8\% $\mathrm{NaCl}$ diet), matching wildtype mice (Fig.7D). Use of hexamethonium revealed that $20 \mathrm{~mm} \mathrm{Hg}$ of the

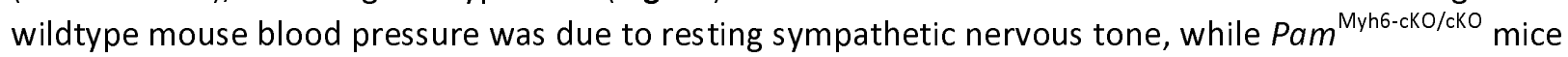
lacked any resting sympathetic tone (Fig.7F). Pam ${ }^{\mathrm{Myh6}-\mathrm{cKO} / \mathrm{cKO}}$ mice have negligible circulating ANP (Fig.7B), as in ANP and Corin knockout mice, which exhibit salt-induced hypertension of $15-30 \mathrm{~mm} \mathrm{Hg}$ $(28,38,76)$. ANP and BNP are released from the atrium in response to cardiac distension $(38,56)$. Wildtype mice fed solid diets containing $0.49 \%$ (normal) and $8 \%$ (high) NaCl show no detectable elevation in arterial blood pressure in most studies $(28,38,76)$; only $25 \%$ of normotensive humans are salt sensitive, by the American Heart Association (77).

ANP, vasopressin, angiotensin II, bradykinin and neuropeptide $\mathrm{Y}$ are the dominant peptides controlling blood pressure responses to dietary salt and altered cardiovascular volume $(38,56,58)$. Only vasopressin and NPY require amidation for bioactivity, and both elevate blood pressure, so loss of amidation could decrease blood pressure. ANP works in opposition to the sympathetic system, attenuating vascular tone, inhibiting vasopressin release, reducing renin release and decreasing 
angiotensinogen conversion into angiotensin $(38,56,58)$. Since circulating renin levels were unaltered in Pam ${ }^{\mathrm{Myh6}-\mathrm{cKO} / \mathrm{cKO}}$ mice (Fig.7E), we hypothesize that lack of sympathetic tone (Fig.7F) counterbalances loss of circulating ANP (Fig.7C).

Transcript changes in atria of Pam $^{\mathrm{Myh6-cko/cko}}$ mice: Levels of about 550 atrial transcripts were significantly altered in Pam ${ }^{\mathrm{Myh6}-\mathrm{cKO} / \mathrm{cKO}}$ mice (Fig.8, Suppl.Fig.8, Suppl.Tables 3,4), just over $2 \%$ of the genome. Altered transcript levels may underlie some of the physiological changes seen in Pam ${ }^{\text {Myh6-cko/cko }}$ mice, such as increased anxiety, heightened ability to withstand a cold challenge, and lack of increased blood pressure on an $8 \% \mathrm{NaCl}$ diet (Figs.6,7). One interesting transcript increased in $\mathrm{Pam}^{\mathrm{Myh6}-\mathrm{cKO} / \mathrm{ckO}}$ mice encodes apelin, a secreted protein. Signal peptide removal yields proapelin, a 55 amino acid protein; the 13 amino acid $\mathrm{COOH}$-terminal peptide that binds to the APJ receptor is preceded by a furin-like cleavage site expected to generate an amidated 34 amino acid product. After experimentally-induced pressure overload due to aortic banding, Apln knockout mice exhibit severely reduced cardiac contractility (78).

The generation of a PAM-derived $\mathrm{COOH}$-terminal fragment called SfCD, which enters the nucleus (26), led to studies on the effects of PAM on gene expression. We know from our studies in a doxycyclineinducible corticotrope tumor cell line that a 2-day 100-fold increase in PAM expression (up close to the level in the adult atrium) altered the expression of a few hundred genes (10). The altered atrial gene expression observed here could reflect the absence of PAM itself or a compensatory response to the consequences of lacking PAM expression since conception. It is particularly interesting to note the large number of transcripts which change in response to altered PAM expression in both pituitary cells and atrium. Of the 100 transcripts most altered in the atrium by PAM deletion since conception (quadrants $L$ and $\mathrm{R}$ in Fig.8A, with DESeq $2 \mathrm{p}<0.05$ and more than a 2-fold change), over a third were also responsive to a $48 \mathrm{~h}$ increase in PAM expression in pituitary cells (10). A majority of these changes correlated with PAM levels in these two very different model systems. 


\section{FIGURE LEGENDS}

Fig.1. Mice from both Cre-driver lines grow and move normally. Growth Curves. A. The growth of male $(\mathrm{N}=15)$ and female ( $\mathrm{N}=16) \mathrm{Pam}^{\mathrm{Em} \times 1-\mathrm{cKO} / \mathrm{cKO}}$ mice was indistinguishable from wildtype (WT) littermates. $\mathrm{B}$. $\mathrm{Pam}^{\mathrm{Myh} 6-\mathrm{ckO} / \mathrm{kKO}}$ males were larger than wildtype male littermates $(\mathrm{N}=16)$, while the corresponding females were indistinguishable from wildtype females ( $N=18)$. C. Open Field locomotor activity. Ambulations (beam breaks) were recorded over a 30 min period: $C O N, n=43 ; P^{\text {Em }}{ }^{\text {Em1-cKO/+ }}, n=22$;

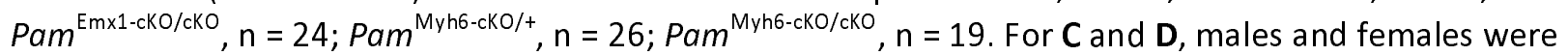
pooled since they were indistinguishable. D. Rotarod. Longest time to fall from the accelerating Rotarod on each test day is plotted: Control (CON), $\mathrm{n}=22 ;$ Pam $^{\mathrm{Em} \times 1-\mathrm{cKO} /+}, \mathrm{n}=8 ; \mathrm{Pam}^{\mathrm{Em} \times 1-\mathrm{cKO} / \mathrm{cKO}}, \mathrm{n}=16$; Pam $^{\text {MyhG- }}$ ${ }^{\mathrm{cKO} /+}, \mathrm{n}=16 ;$ Pam $^{\mathrm{Myh}-\mathrm{ckO} / \mathrm{cKO}}, \mathrm{n}=8$.

Fig.2. Enzyme assays and Western blots demonstrate tissue-specific elimination of PAM expression. PHM (A) and PAL (B) activity assays. Data, as pmol product produced/ $\mu \mathrm{g}$ lysate protein/hour, are composites of three or more PHM assays and two or more PAL assays of lysates prepared from $\geq 6$ mice.

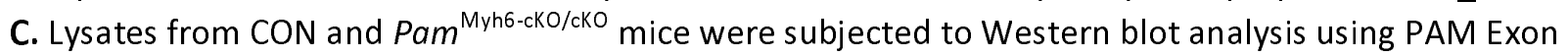
16 antibody; the samples shown were analyzed on the same gel, using lqgap as a loading control. The exposure time shown for the atrial samples was $10 \mathrm{sec}$, to keep the image in the linear range. D. Lysates $\left(20 \mu \mathrm{g}\right.$ protein, except atrium, $5 \mu \mathrm{g}$ ) prepared from the indicated tissues from WT and Pam ${ }^{\mathrm{Em} \times 1 \text {-cko/cko }}$ mice were analyzed in the same manner, with equal loading demonstrated by Coomassie staining. $\mathrm{E}$. Western blot data for PAM1 and SPHM were quantified from multiple gel sets; for each gel set, band intensities for knockout tissues were normalized to the corresponding WT band intensity, which was set to 1.00. Data from at least 3 different sample sets were quantified.

Fig.3. Behavioral/physiological tests of Pam $^{\mathrm{Em} \times 1-\mathrm{ckO} / \mathrm{ckO}}$ mice. A. Anxiety-like behavior. Mice ranged from 60 to 88 days old. Control, $n=48 ;$ Pam $^{\mathrm{Em} \times 1-\mathrm{cKO} /+}, \mathrm{n}=24 ;$ Pam $^{\mathrm{Em} \times 1-\mathrm{cKO} / \mathrm{cKO}}, \mathrm{n}=24$. Data for global Pam heterozygotes $\left(\mathrm{Pam}^{\mathrm{KO} /+}\right.$ ) derived from Emx1-Cre parents (this work) did not differ from data obtained in our previous study (red arrow, $\mathrm{Pam}^{\mathrm{KO} /+}$ ) (14). B. Locomotor response to cocaine. Ambulations were recorded for $45 \mathrm{~min}$ after an intraperitoneal injection of saline (Day 1) or cocaine (20 mg/kg on Day 2; 10 $\mathrm{mg} / \mathrm{kg}$ on Days 3, 4, 5 and 10). Mice ranged from 68 to 151 days old. WT, $\mathrm{n}=8 ;$ Pam $^{\text {Emx1-cko/cko }}, \mathrm{n}=8$. RM-ANOVA was used to compare knockout to WT. C. Core body temperature. Temperature was measured using a rectal thermometer. WT, $n=10 ; P^{\text {am }}{ }^{\text {Em1-cKO/cKO }}, \mathrm{n}=20$. Mice ranged from 67 to 134 days old. Student's t-test applied for the $3 \mathrm{~h}$ data. Previous data from global Pam heterozygotes $\left(\mathrm{Pam}^{\mathrm{KO} /+}\right)$ are shown by the red arrow $\left(\mathrm{Pam}^{\mathrm{KO} /+}\right)(14)$.

Fig.4. PAM is expressed in all Emx-1 expressing (excitatory) neurons. Adult mice expressing a TdTomato Cre-reporter construct and Emx1-Cre were perfusion fixed; coronal sections were stained for PAM using affinity-purified Exon 16 antibody and AlexaFluor488-tagged secondary antibody (green), while nuclei were visualized using Hoechst stain (blue). Images shown are single plane confocal images. A. Diagram of the hippocampus and major pathways; boxed areas indicate the regions of CA1 and CA3 examined. B. CA1 region. C. CA3 region. D. Cortex layer 2. E. Cortex layer 5. All TdTomato-positive neurons were also PAM-positive (yellow arrows). A fraction of the PAM-positive neurons did not express TdTomato (green arrows). Abbreviations: stratum oriens, SO; stratum pyramidale, Pyr; stratum radiatum, SR; lacunosum moleculare, LM; mf, mossy fiber. Scale bars, $50 \mu \mathrm{m}$ (hippocampus) and $20 \mu \mathrm{m}$ (cortex). F. Cell Counts. Cortical images from two mice were quantified (4-5 images per region per 
animal, 141-213 nuclei per layer per animal): the number of TdTomato/PAM-positive cells and TdTomato-negative/PAM-positive cells is expressed as a percentage of nuclei (Hoechst stained).

Fig.5. Many of the PAM-positive neurons that remain in the hippocampus and cortex of Pam ${ }^{\text {Emx1- }}$ cKo/cko mice express GAD. Sections stained with affinity-purified PAM-Exon 16 antibody plus AlexaFluor488-antibody to rabbit IgG (green), mouse monoclonal antibody to GAD67 plus Cy3-antibody to mouse IgG (red), and Hoechst nuclear stain (blue). CA3 regions of WT (A.) and KO (B.) hippocampus; yellow arrows mark neurons stained for PAM and GAD67. WT (C.) and KO (D.) layer 2 and KO layer 5 (E.) visualized as described for hippocampus. Scale bars, $50 \mu \mathrm{m}$ (hippocampus) and $20 \mu \mathrm{m}$ (cortex). In KO layer 2, all GAD-positive neurons were PAM-positive; in KO layer 5, some PAM-positive neurons were not GAD-positive (white arrows). Quantification is in Supplemental Table 2.

Fig.6. Behavioral/physiological tests of Pam ${ }^{\mathrm{Myh6-cko/cKO}}$ mice. Pam ${ }^{\mathrm{Myh6-cKO/cKO}}$ mice were tested along with the mice reported in Fig.3; control data are replicated here. A. Anxiety-like behavior. Mice ranged from 60 to 88 days old. Control, $n=48 ;$ Pam $^{\mathrm{Myh6-ckO/+}}, \mathrm{n}=20 ;$ Pam $^{\mathrm{Myh6}-\mathrm{ckO} / \mathrm{ckO}}, \mathrm{n}=30$. Data obtained previously for $\mathrm{Pam}^{\mathrm{KO} /+}$ are shown (red arrow) (14). B. Locomotor response to cocaine. Ambulations after an intraperitoneal injection of saline or cocaine were recorded as described in Fig.3. Mice ranged from 61 to 114 days old. WT, $n=8$; Pam ${ }^{\mathrm{Myh6}-\mathrm{ckO} / \mathrm{ckO}}, \mathrm{n}=12$. RM-ANOVA was used to compare knockout to Control. C. Core body temperature. WT, $n=10 ; P^{M a m}{ }^{\mathrm{Myh} 6-\mathrm{cKO} / \mathrm{cKO}}, \mathrm{n}=10$. Mice ranged from 67 to 134 days old. Student's t-test applied for the $3 \mathrm{~h}$ data. Previous data for $\mathrm{Pam}^{\mathrm{KO} /+}$ are shown by the red arrow (14). D. Abdominal and tail temperatures during $\mathbf{2 0}$ min restraint in an unfamiliar environment. Abdominal temperatures were determined at the beginning and end of 20 min restraint, and tail temperatures were determined throughout the experiment. The difference (Abdomen minus tail) at 0 and 20 min is shown. CON, n=20; Pam $^{\mathrm{Myh6}-\mathrm{cKO} / \mathrm{cKO}}, \mathrm{n}=23$.

Fig.7. Alterations in proANP and blood pressure regulation in Pam ${ }^{\mathrm{Myh6-cko/cKo}}$ mice. A. RIPA lysates of four pairs of WT and Pam ${ }^{\mathrm{Myh6}-\mathrm{cKO} / \mathrm{cKO}}$ atria (1 $\mu \mathrm{g}$ protein/lane) were fractionated by SDS-PAGE and analyzed for PAM (PAM-1 specific antibody JH629; PAM cytosolic domain antibody, C-Stop) and proANP; the gel that was analyzed using the ANP-specific antibody had $10 \mu \mathrm{g}$ protein/lane. Graph shows quantification, relative to WT. B. ANP ELISAs confirmed the drop in ANP levels in atrial extracts and trunk blood ( $\mathrm{N}=10$ for serum, 14 for tissue). C. PHM assays on serum samples from WT and Pam Myh6cko/ckO mice (WT n=3; Pam ${ }^{\mathrm{Myh} 6-\mathrm{ckO} / \mathrm{cKO}}, \mathrm{n}=3$ ). Similar results were obtained in a second assay comparing these mice, as well as sera from WT and Pam ${ }^{\mathrm{Em} \times 1-\mathrm{cKO} / \mathrm{cKO}}$ mice (not shown). D. High Salt Diet. Tail cuff

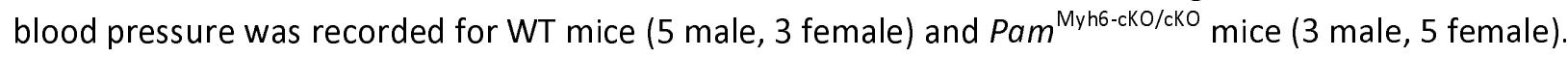
Mice were maintained for $>2$ months on a normal salt diet $(0.49 \% \mathrm{NaCl}), 7$ days on a solid diet including $8 \% \mathrm{NaCl}$ (High Salt), during which body weight and food consumption remained constant, followed by an additional week on the normal salt diet. Mice were 79-101 days old. The experiment was repeated with WT mice ( 2 male, 2 female) and Pam ${ }^{\mathrm{Myh6}-\mathrm{ckO} / \mathrm{ckO}}$ mice ( 2 male, 2 female) with the same results. E. Serum renin was measured by ELISA, with $16 \mathrm{WT}$ and $16 \mathrm{Pam}^{\mathrm{Myh}-\mathrm{ckO} / \mathrm{ckO}}$ samples. F. Tail cuff blood pressure was recorded $10 \mathrm{~min}$ after an injection of isotonic saline (Day 1) and after an injection of hexamethonium (Day 2) (38, 39). The average difference between the Day 1 and Day 2 data for each mouse is plotted.

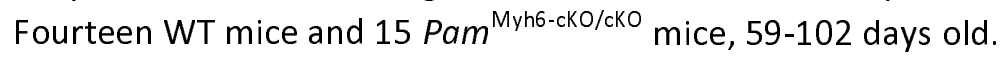

Fig.8. RNAseq of Atrial RNA. A. Volcano plot of all transcripts with FPKM $>1$, comparing WT and Pam ${ }^{\text {Myh6- }}$ cKO/cKO samples; the horizontal blue line indicates the cutoff for DESeq2 significance $(p<0.05)$, while the vertical blue lines indicate transcripts changed at least 2-fold up or down, comparing WT and Pam ${ }^{\text {Myh6- }}$ 
cKO/ckO samples. X-axis is Log2 of the ratio (WT/KO); Y-axis is -Log10 of the DESeq2 $\mathrm{p}$ value (up is more significant). Transcripts with blue dots were decreased when PAM was induced in pituitary cells in our previous study (10), while red dots indicate transcripts increased when PAM was induced. Grey dots indicate transcripts expressed at low levels in pituitary cells (FPKM $<3$ ). B,C. From Ingenuity Pathway Analysis, two of the most significant networks were centered on the Apelin peptide and on circadian rhythms. The $y$-axes of the bar graphs on the left show $\log _{2}$ of the $\mathrm{Wt} / \mathrm{KO}$ ratio. The $\mathrm{y}$-axes of the bar graphs on the right show $\log _{2}$ of the FPKM values for each transcript in Wt and KO, along with the DESeq2 p value. Code: *, significant in pituitary cells (10); N, no change in pituitary cells; 0 , not expressed above $F P K M=2$ in pituitary cells; $X$, opposite response in pituitary cells.

\section{Acknowledgments}

We thank Dr. Nils Bäck for the broad perspective he provided as he offered comments on this manuscript and members of the Neuropeptide Lab for many helpful discussions. This work was supported by NIH Grants R01DK032948 and R01DK032949, the Janice and Rodney Reynolds Endowment and the Daniel Schwartzberg Fund. 


\section{$\underline{\text { References }}$}

1. A. Senatore, T. S. Reese, C. L. Smith, Neuropeptidergic integration of behavior in Trichoplax adhaerens, an animal without synapses. J Exp Biol 220, 3381-3390 (2017).

2. F. Varoqueaux et al., High Cell Diversity and Complex Peptidergic Signaling Underlie Placozoan Behavior. Curr.Biol. 28, 3495-3501 (2018).

3. M. P. Nusbaum, D. M. Blitz, E. Marder, Functional consequences of neuropeptide and smallmolecule co-transmission. Nat.Rev.Neurosci. 18, 389-403 (2017).

4. B. Ramos-Molina, M. G. Martin, I. Lindberg, PCSK1 Variants and Human Obesity. Prog.Mol.Biol.Transl.Sci. 140, 47-74 (2016).

5. L. D. Fricker, Carboxypeptidase $E$ and the Identification of Novel Neuropeptides as Potential Therapeutic Targets. Adv.Pharmacol. 82, 85-102 (2018).

6. X. Liang, T. E. Holy, P. H. Taghert, A Series of Suppressive Signals within the Drosophila Circadian Neural Circuit Generates Sequential Daily Outputs. Neuron 94, 1173-1189 (2017).

7. Y. Nakagawa, T. Nishikimi, K. Kuwahara, Atrial and brain natriuretic peptides: Hormones secreted from the heart. Peptides 111, 18-25 (2019).

8. D. Kumar, R. E. Mains, B. A. Eipper, 60 years of POMC: From POMC and $\alpha-M S H$ to PAM, molecular oxygen, copper, and vitamin C. J.Mol.Endocrinol. 56, T63-T76 (2016).

9. K. Tatemoto, M. Carlquist, V. Mutt, Neuropeptide Y, a novel brain peptide with structural similarities to peptide YY and pancreatic polypeptide. Nature 296, 659-660 (1982).

10. R. E. Mains, C. Blaby-Haas, B. A. Rheaume, B. A. Eipper, Changes in Corticotrope Gene Expression Upon Increased Expression of Peptidylglycine alpha-Amidating Monooxygenase. Endocrinology 159, 2621-2639 (2018).

11. T. A. Czyzyk et al., Deletion of peptide amidation enzymatic activity leads to edema and embryonic lethality in the mouse. Dev. Biol 287, 301-313 (2005).

12. N. Jiang et al., PHM is required for normal developmental transitions and for biosynthesis of secretory peptides in drosophila. Dev. Biol 226, 118-136 (2000).

13. D. Kumar et al., Microvillar and ciliary defects in zebrafish lacking an actin-binding bioactive peptide amidating enzyme. Sci.Rep. 4, 4547 (2018).

14. D. Bousquet-Moore et al., Interactions of peptide amidation and copper: novel biomarkers and mechanisms of neural dysfunction. Neurobiol. Dis 37, 130-140 (2010).

15. M. K. H. Schafer, D. A. Stoffers, B. A. Eipper, S. J. Watson, Expression of PAM in the rat central nervous system. J. Neurosci 12, 222-234 (1992).

16. J. A. Gorski et al., Cortical Excitatory Neurons and Glia, But Not GABAergic Neurons, Are Produced in the Emx1-Expressing Lineage. J.Neurosci. 22, 6309-6314 (2002).

17. P. Li et al., Loss of CLOCK Results in Dysfunction of Brain Circuits Underlying Focal Epilepsy. Neuron 96, 387-401 (2017).

18. D. A. Stoffers, C. B. Green, B. A. Eipper, Alternative mRNA splicing generates multiple forms of peptidyl- glycine alpha-amidating monooxygenase in rat atrium. Proc. Natl. Acad. Sci. U. S. A 86, 735-739 (1989).

19. R. Agah et al., Gene Recombination in Postmitotic Cells: Targeted Expression of Cre Recombinase Provokes Cardiac-restricted, Site-specific Rearrangement in Adult Ventricular Muscle In Vivo. J.Clin.Invest. 199, 169-179 (1997).

20. J. Palermo, J. Gulick, M. Colbert, J. Fewell, J. Robbins, Transgenic Remodeling of the Contractile Apparatus in the Mammalian Heart. Circ.Res. 78, 504-509 (1996).

21. E. D. Gaier et al., Peptidylglycine alpha-amidating monooxygenase heterozygosity alters brain copper handling with region specificity. J. Neurochem 127, 605-619 (2013). 
22. K. S. Vishwanatha, N. Bäck, T. T. Lam, R. E. Mains, B. A. Eipper, O-Glycosylation of a Secretory Granule Membrane Enzyme Is Essential for Its Endocytic Trafficking. J.Biol.Chem. 291, 9835-9850 (2016).

23. M. B. Miller et al., Brain region and isoform-specific phosphorylation alters Kalirin $\mathrm{SH} 2$ domain interaction sites and calpain sensitivity. ACS Chem. Neurosci. 8, 1554-1569 (2017).

24. C. C. Glembotski, C. E. Irons, A. B. Sprenkle, C. A. Sei, Studies of ANF Processing and Secretion Using a Primary Cardiocyte Culture Model. Can. J. Physiol. Pharmacol 69, 1525-1536 (1990).

25. P. P. Shields, C. C. Glembotski, The Post-translational Processing of Rat Pro-atrial Natriuretic Factor by Primary Atrial Myocyte Cultures. J. Biol. Chem 263, 8091-8098 (1988).

26. C. Rajagopal, K. L. Stone, V. P. Francone, R. E. Mains, B. A. Eipper, Secretory Granule to the Nucleus: role of a multiply phosphorylated intrinsically unstructured domain. J.Biol.Chem. 284, 25723-25734 (2009).

27. I. R. Sarda, M. L. de Bold, A. J. de Bold, Optimization of Atrial Natriuretic Factor Radioimmunoassay Clin.Biochem. 22, 11-15 (1989).

28. S. W. M. John et al., Genetic decreases in atrial natriuretic peptide and salt-sensitive hypertension. Science 267, 679-681 (1995).

29. P. Mandela, Y. Yan, T. Larese, B. A. Eipper, R. E. Mains, Elimination of Kalrn Expression in POMC Cells Reduces Anxiety-Like Behavior and Contextual Fear Learning. Horm. Behav 66, 430-438 (2014).

30. X. M. Ma, R. E. Mains, B. A. Eipper, Plasticity in hippocampal peptidergic systems induced by repeated electroconvulsive shock. Neuropsychopharmacology 27, 55-71 (2002).

31. X. M. Ma, Y. Wang, F. Ferraro, R. E. Mains, B. A. Eipper, Kalirin-7 Is an Essential Component of both Shaft and Spine Excitatory Synapses in Hippocampal Interneurons. J. Neurosci 28, 711-724 (2008).

32. X. M. Ma et al., Kalirin-7 Is Required for Synaptic Structure and Function. J. Neurosci 28, 1236812382 (2008).

33. D. D. Kiraly, X. M. Ma, C. M. Mazzone, X. Xin, R. E. Mains, Behavioral and Morphological Responses to Cocaine Require Kalirin7. Biol. Psychiatry 68, 249-255 (2010).

34. T. LaRese, B. A. Rheaume, R. Abraham, B. A. Eipper, R. E. Mains, Sex-Specific Gene Expression in the Mouse Nucleus Accumbens Before and After Cocaine Exposure. J.Endocr.Soc. 3, 468-487 (2019).

35. D. M. L. Vianna, P. Carrive, Changes in cutaneous and body temperature during and after conditioned fear to context in the rat. Eur.J.Neurosci. 21, 2505-2512 (2005).

36. R. A. Piñol et al., Brs3 neurons in the mouse dorsomedial hypothalamus regulate body temperature, energy expenditure, and heart rate, but not food intake. Nat.Neurosci. 21, 15301540 (2018).

37. S. E. Whitesall, J. B. Hoff, A. P. Vollmer, L. G. D'Alecy, Comparison of simultaneous measurement of mouse systolic arterial blood pressure by radiotelemetry and tail-cuff methods. Am.J.Physiol. 286, H2408-H2415 (2004).

38. L. G. Melo, M. E. Steinhelper, S. C. Pang, M. Y. Tse, U. Ackermann, ANP in regulation of arterial pressure and fluid electrolyte balance: lessons from genetic mouse models. Physiol.Genomics 3, 45-58 (2000).

39. J. Zacharia, J. R. H. Mauban, H. Raina, S. A. Fisher, W. G. Wier, High Vascular Tone of Mouse Femoral Arteries In Vivo Is Determined by Sympathetic Nerve Activity Via alpha-1A- and alpha1D-Adrenoceptor Subtypes. PLOS ONE 8, e65969 (2013).

40. M. I. Love, W. Huber, S. Anders, Moderated estimation of fold change and dispersion for RNAseq data with DESeq2. Genome Biol. 15, 550 (2014). 
41. X. Gu, Statistical detection of differentially expressed genes based on RNA-seq: from biological to phylogenetic replicates. Brief.Bioinform. 17, 243-248 (2016).

42. E. D. Gaier et al., In vivo and in vitro analyses of amygdala function reveal a role for copper. J. Neurophysiol 111, 1927-1939 (2014).

43. S. L. Robinson, T. E. Thiele, The Role of Neuropeptide Y (NPY) in Alcohol and Drug Abuse Disorders. Int. Rev. Neurobiol. 136, 177-197 (2017).

44. D. A. Perrey, Y. Zhang, Therapeutics development for addiction: Orexin-1 receptor antagonists. Brain Res. PMID: 30148984; doi: 10.1016/j.brainres.2018.08.025. (2018).

45. S. J. Simmons, T. A. Gentile, Cocaine abuse and midbrain circuits: Functional anatomy of hypocretin/orexin transmission and therapeutic pros and cons. Brain Res. PMID: 3079689 (2019).

46. M. H. James, S. V. Mahler, D. E. Moorman, G. Aston-Jones, A Decade of Orexin/Hypocretin and Addiction: Where Are We Now? Curr. Topics Behav. Neurosci. 33, 247-282 (2017).

47. C. A. Pedersen, Oxytocin, Tolerance, and the Dark Side of Addiction. Int.Rev.Neurobiol. 136, 239274 (2017).

48. S. M. Tyree, L. de Lecea, Lateral Hypothalamic Control of the Ventral Tegmental Area: Reward Evaluation and the Driving of Motivated Behavior. Front.Sys.Neurosci. 11, 50 (2017).

49. S. B. G. Abbott, C. B. Saper, Median preoptic glutamatergic neurons promote thermoregulatory heat loss and water consumption in mice. J.Physiol. 595, 6569-6583 (2017).

50. J. Siemens, G. B. Kamm, Cellular populations and thermosensing mechanisms of the hypothalamic thermoregulatory center. Pflügers Arch. 470, 809-822 (2018).

51. E. Muth, W. J. Driscoll, A. Smalstig, G. Goping, G. P. Mueller, Proteomic analysis of rat atrial secretory granules: a platform for testable hypotheses. Biochim. Biophys. Acta 1699, 263-275 (2004).

52. P. J. O'Donnell, W. J. Driscoll, N. Back, E. Muth, G. P. Mueller (2003) Peptidylglycine- $\alpha$-amidating monooxygenase and pro-atrial natriuretic peptide constitute the major membrane-associated proteins of rat atrial secretory granules. in J. Mol. Cell. Cardiol, pp 915-922.

53. V. Labrador, C. Brun, S. Konig, A. Roatti, A. J. Baertschi, Peptidyl-Glycine alpha-Amidating Monooxygenase Targeting and Shaping of Atrial Secretory Vesicles. Circ.Res. 95, e98-e109 (2004).

54. F. Wu, W. Yan, J. Pan, J. Morser, Q. Wu, Processing of pro-atrial natriuretic peptide by corin in cardiac myocytes. J.Biol.Chem. 277, 16900-16905 (2002).

55. S. Fu, P. Ping, F. Wang, L. Luo, Synthesis, secretion, function, metabolism and application of natriuretic peptides in heart failure. J.Biol.Engineering 12, 2 (2018).

56. M. F. McGrath, M. L. K. de Bold, A. J. de Bold, The endocrine function of the heart. Trends Endocr.Metab. 16, 469-479 (2005).

57. K. Sato, T. Numata, T. Saito, Y. Ueta, Y. Okada, V2 receptor-mediated autocrine role of somatodendritic release of AVP in rat vasopressin neurons under hypo-osmotic conditions. Sci. Signal 4/157, ra5 (2011).

58. K. N. Pandey, Molecular and genetic aspects of guanylyl cyclase natriuretic peptide receptor-A in regulation of blood pressure and renal function. Physiol.Genomics 50, 913-928 (2018).

59. A. J. Miller, A. C. Arnold, The renin-angiotensin system in cardiovascular autonomic control: recent developments and clinical implications. Clin.Autonom.Res. PMID: 30413906 DOI: 10.1007/s10286-10018-10572-10285 (2018).

60. P. F. O'Tierney, M. Y. Tse, S. C. Pang, Elevated renal norepinephrine in proANP gene-disrupted mice is associated with increased tyrosine hydroxylase expression in sympathetic ganglia. Regul.Peptides 143, 90-96 (2007). 
61. S. Zhang, F. Zhang, H. Sun, Y. Zhou, Y. Han, Enhanced sympathetic activity and cardiac sympathetic afferent reflex in rats with heart failure induced by adriamycin. J.Biomed.Res. 26, 425-431 (2012).

62. H. Antushevich, M. Wójcik, Review: Apelin in disease. Clin.Chim.Acta 483, 241-248 (2018).

63. A. Nakashima et al., Dec1 and CLOCK Regulate Na+/K+-ATPase $\beta 1$ Subunit Expression and Blood Pressure. Hypertension 72, 746-754 (2018).

64. H. J. Pi et al., Cortical interneurons that specialize in disinhibitory control. Nature 503, 521-524 (2013).

65. Q. Wei et al., Uneven balance of power between hypothalamic peptidergic neurons in the control of feeding. Proc.Natl.Acad.Sci.USA 115, E9489-E9498 (2018).

66. F. Sotres-Bayon, D. E. Bush, J. E. Ledoux, Acquisition of fear extinction requires activation of NR2B-containing NMDA receptors in the lateral amygdala. Neuropsychopharmacology 32, 19291940 (2007).

67. C. M. Fraser, M. J. Cooke, A. Fisher, I. D. Thompson, T. W. Stone, Interactions between ifenprodil and dizocilpine on mouse behaviour in models of anxiety and working memory. Eur. Neuropsychopharmacol. 6, 311-316 (1996).

68. A. Strohle, C. Feller, C. J. Strasburger, A. Heinz, F. Dimeo, Anxiety modulation by the heart? Aerobic exercise and atrial natriuretic peptide. Psychoneuroendocrinology 31, 1127-1130 (2016).

69. C. Herrmann-Lingen et al., High Plasma Levels of N-Terminal Pro-Atrial Natriuretic Peptide Associated With Low Anxiety in Severe Heart Failure. Psychosom. Med. 65, 517-522 (2003).

70. P. W. Kalivas, N. D. Volkow, New medications for drug addiction hiding in glutamatergic neuroplasticity. Mol Psychiatry 16, 974-986 (2011).

71. C. D. Gipson, Y. M. Kupchik, P. W. Kalivas, Rapid, transient synaptic plasticity in addiction. Neuropharmacology 76B, 276-286 (2014).

72. D. M. Walker et al., Cocaine Self-administration Alters Transcriptome-wide Responses in the Brain's Reward Circuitry. Biol. Psychiatry 84, 867-880 (2018).

73. Z. D. Zhao et al., A hypothalamic circuit that controls body temperature. Proc.Natl.Acad.Sci.USA 114, 2042-2047 (2017).

74. A. Morelli et al., Metabolic syndrome induces inflammation and impairs gonadotropin-releasing hormone neurons in the preoptic area of the hypothalamus in rabbits. Mol.Cell.Endocrinol. 382, 107-119 (2014).

75. D. Xi et al., Ablation of Oxytocin Neurons Causes a Deficit in Cold Stress Response. J.Endocr.Soc. 1, 1041-1055 (2017).

76. J. C. Y. Chan et al., Hypertension in mice lacking the proatrial natriuretic peptide convertase corin. Proc.Natl.Acad.Sci.USA 102, 785-790 (2005).

77. T. W. Kurtz, S. E. DiCarlo, M. Pravenec, C. Morris, An Appraisal of Methods Recently Recommended for Testing Salt Sensitivity of Blood Pressure. J.Am.Heart Assoc. 6, e005653 (2017).

78. K. Kuba et al., Impaired heart contractility in Apelin gene-deficient mice associated with aging and pressure overload. Circ.Res. 101, e32-e42 (2007). 
A. Emx1

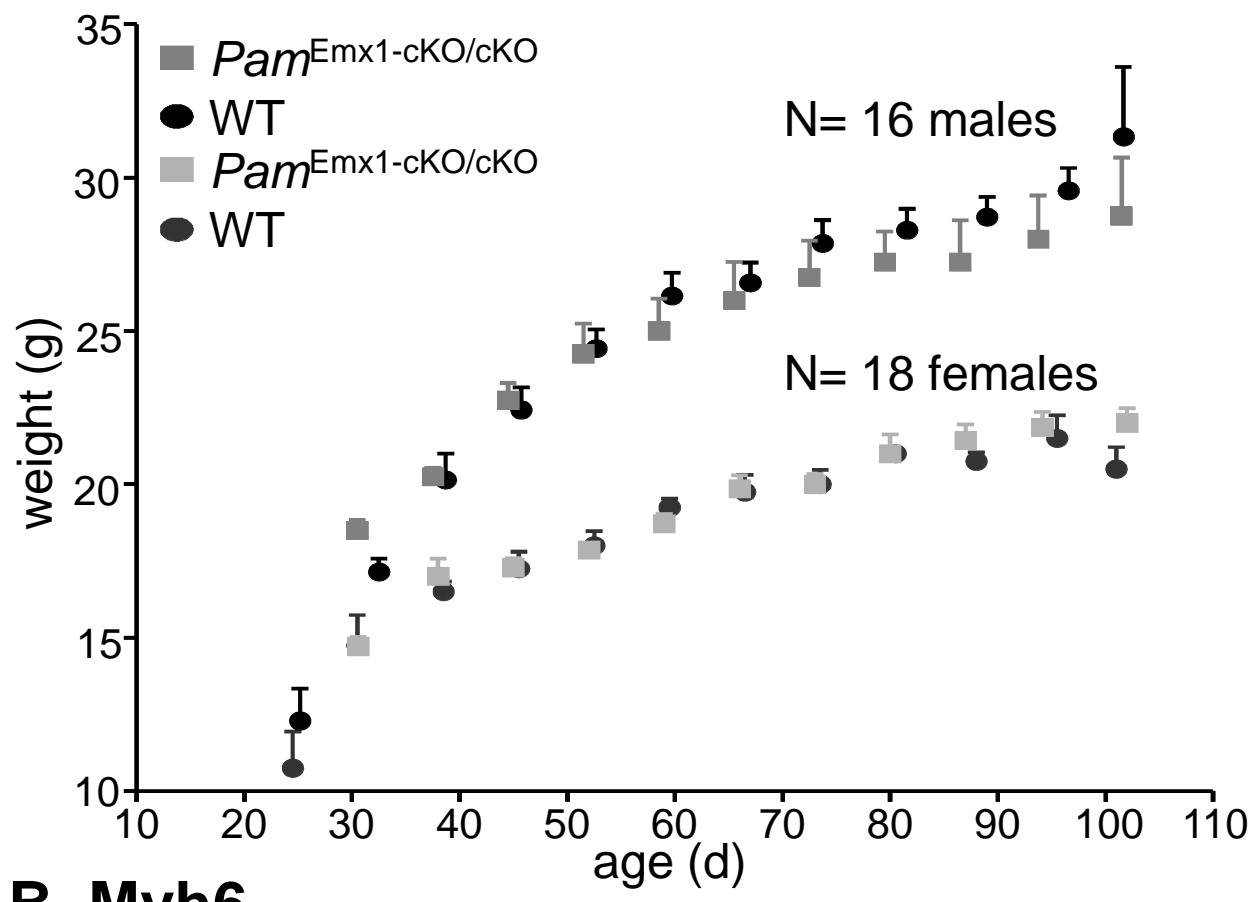

\section{B. Myh6}

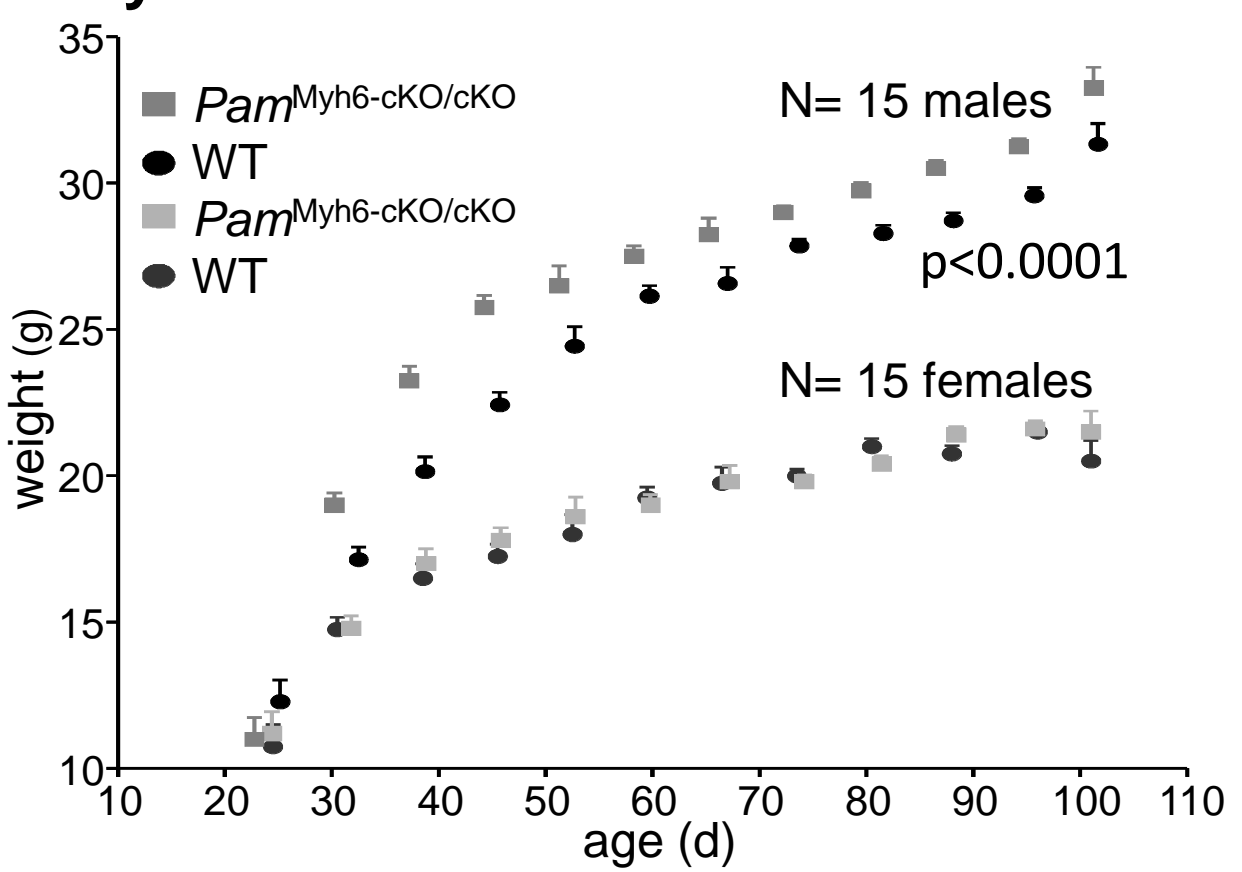

\section{Open Field}

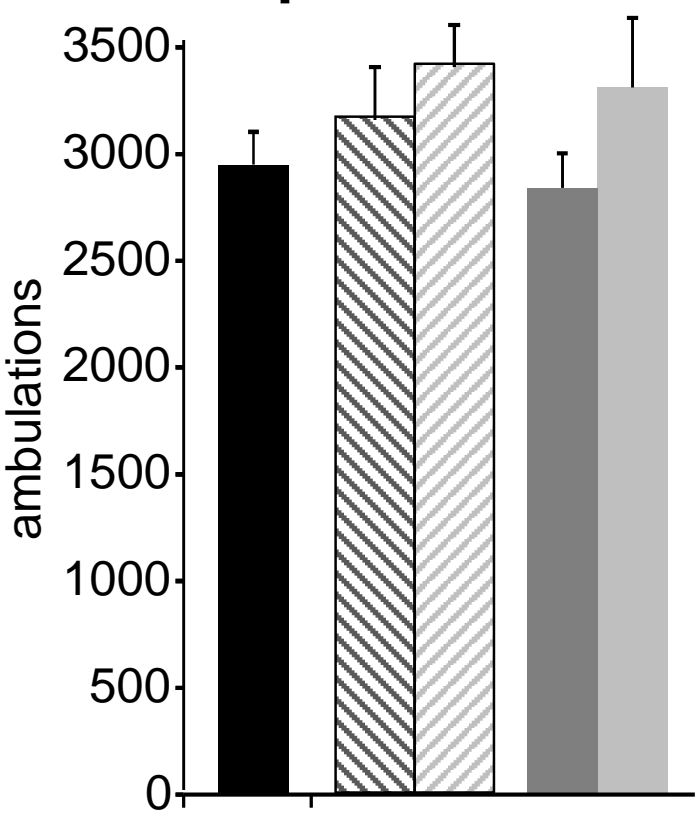

CON

$\triangle$ Pam $^{\mathrm{Em} \times 1-\mathrm{ckO} /+}$

$\triangle$ Pam $^{\mathrm{Em} \times 1-\mathrm{cKO} / \mathrm{ckO}}$

$\square$ Pam $^{\mathrm{Myh6} \text {-ckO/+ }}$

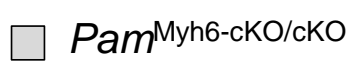

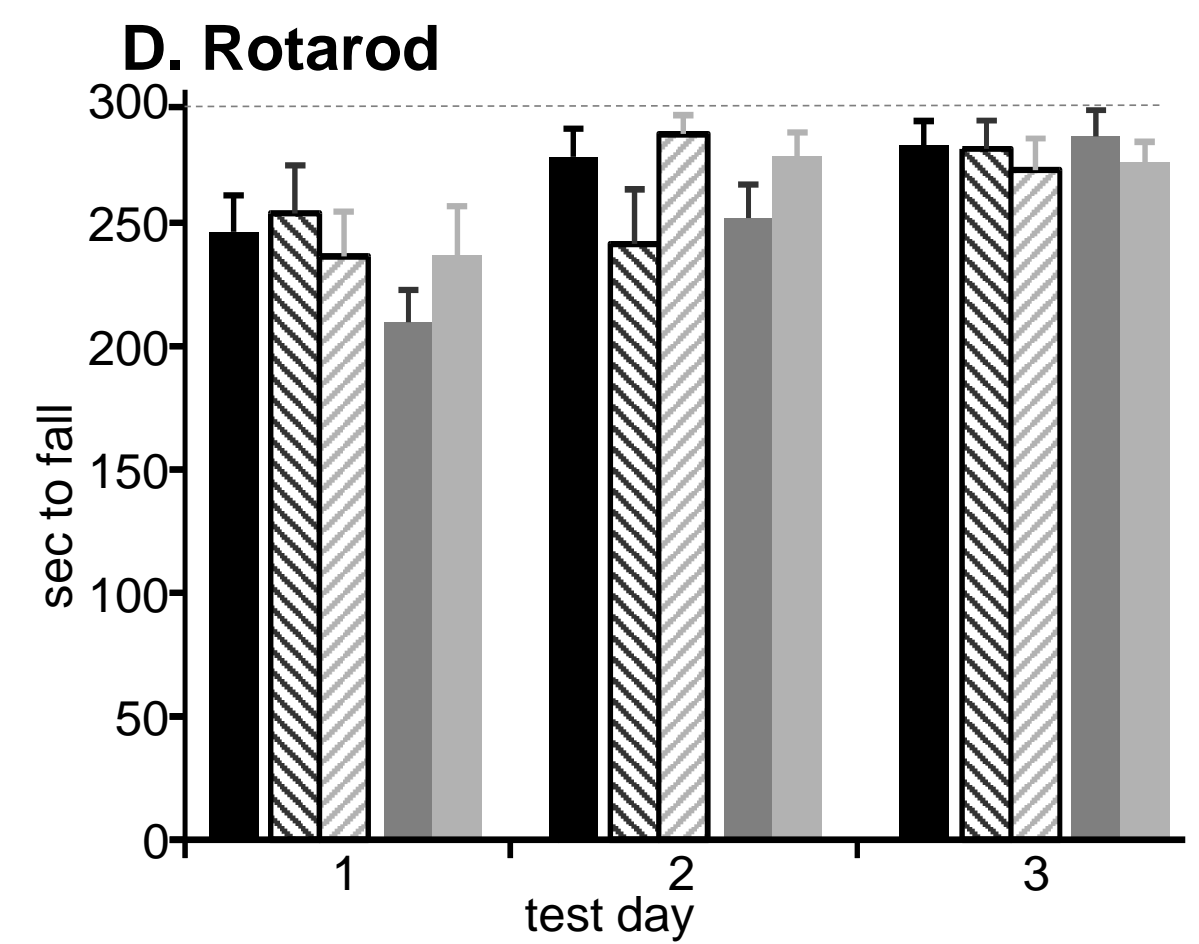




\section{A. PHM Activity}

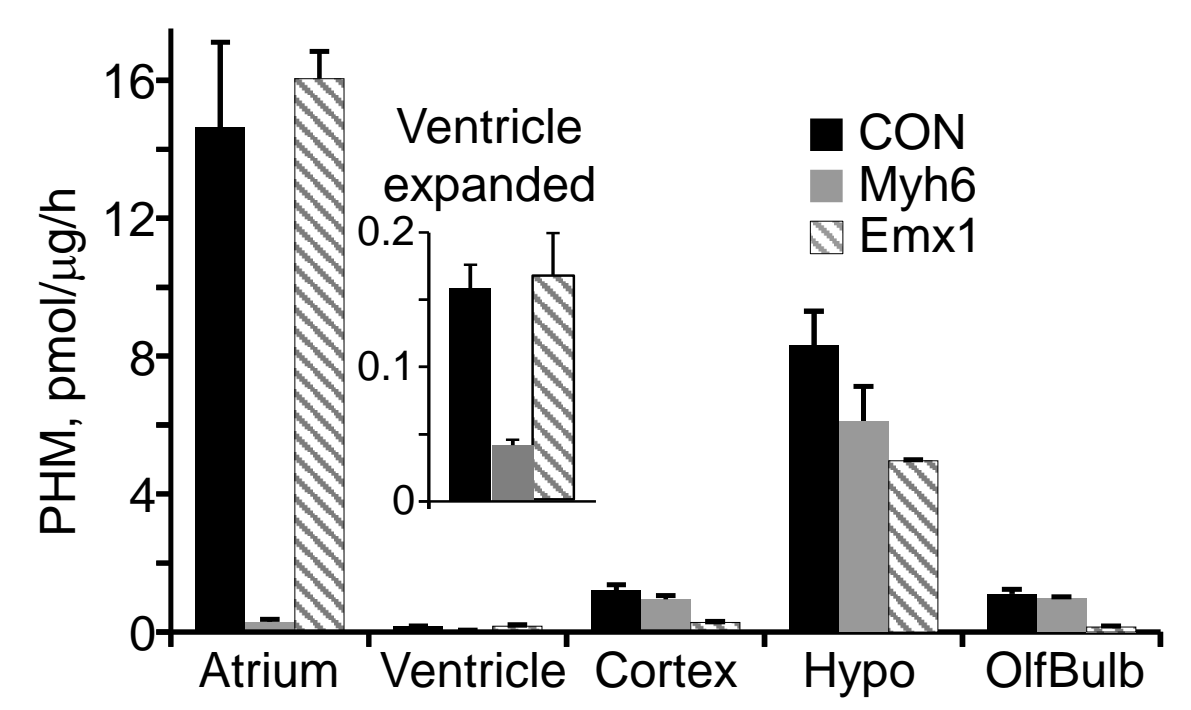

\section{B. PAL Activity}

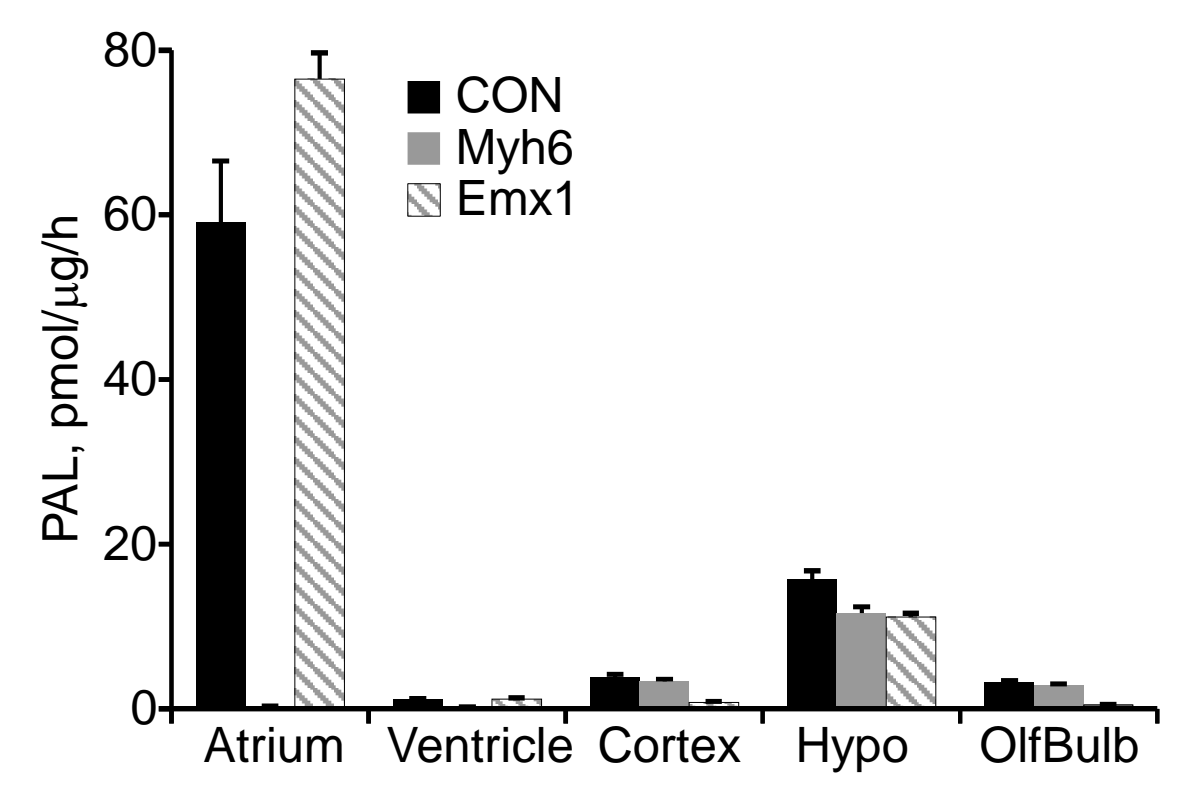

C. WT vs. Pam ${ }^{\text {Myh6-cko/cko }}$

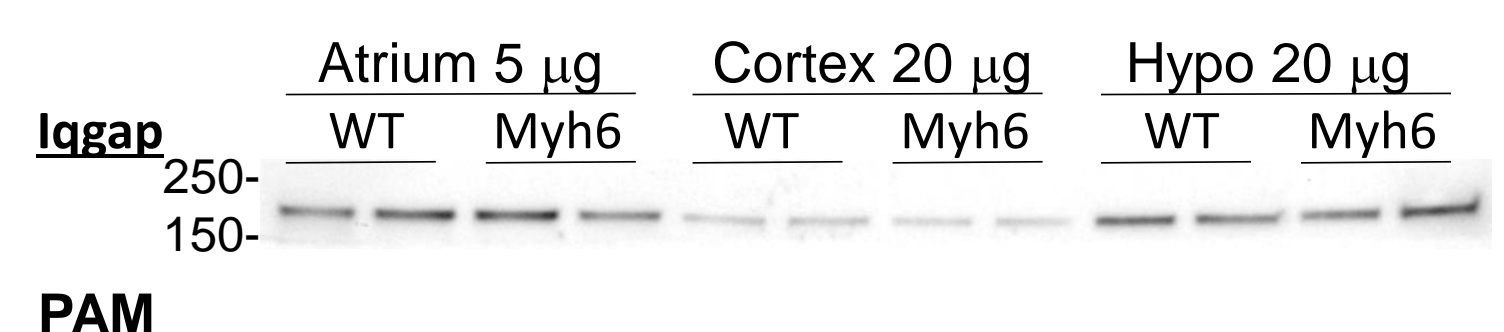

$$
\begin{array}{r}
\mathrm{PAM}_{100-}^{150-} \\
75- \\
\mathrm{SPHM} \rightarrow 30- \\
57-
\end{array}
$$

D. WT vs. Pam Emx1-cko/cko

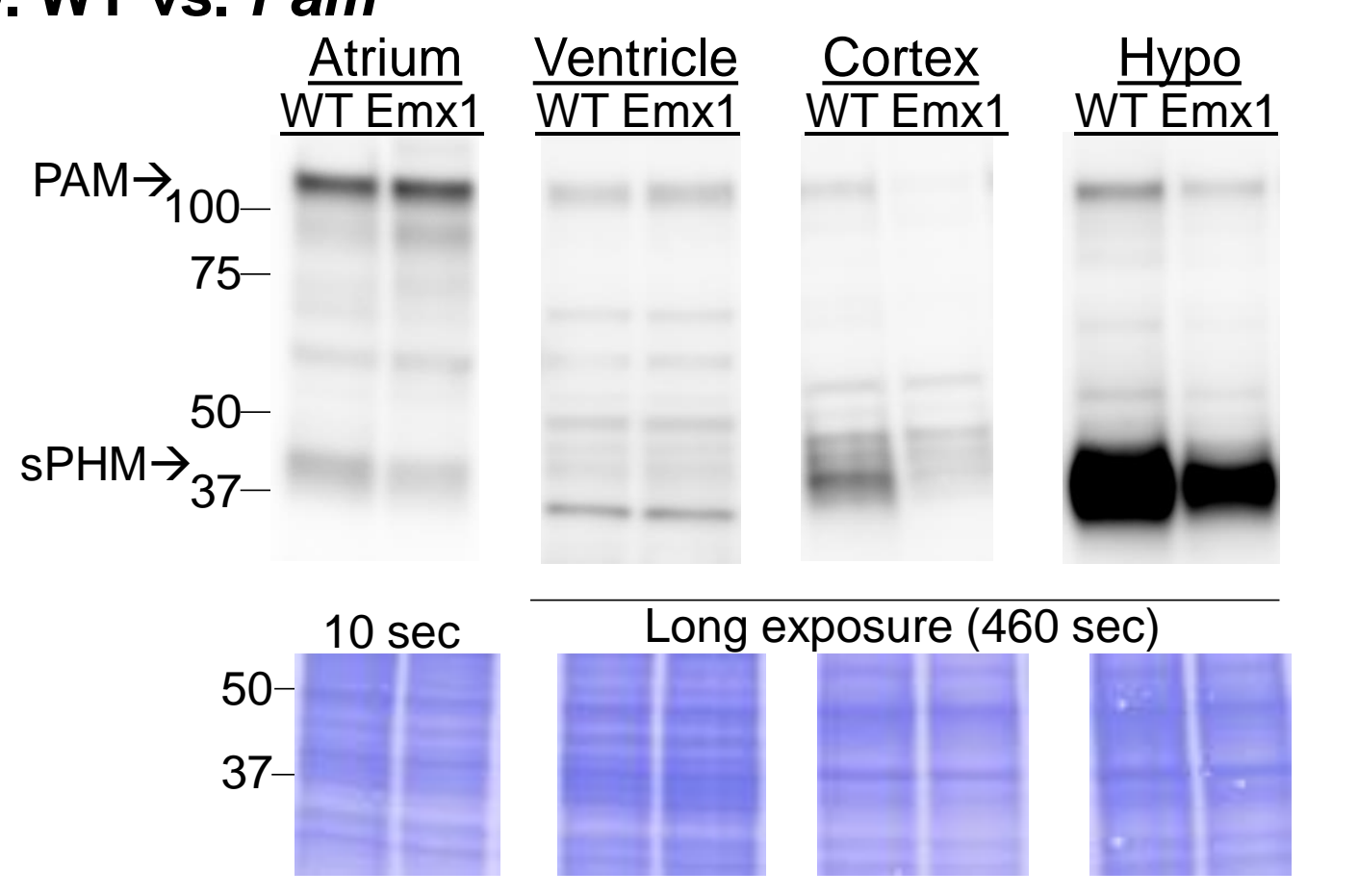

E. - $\mathrm{CON}=\mathrm{Myh} 6 \triangle \mathrm{Emx} 1$
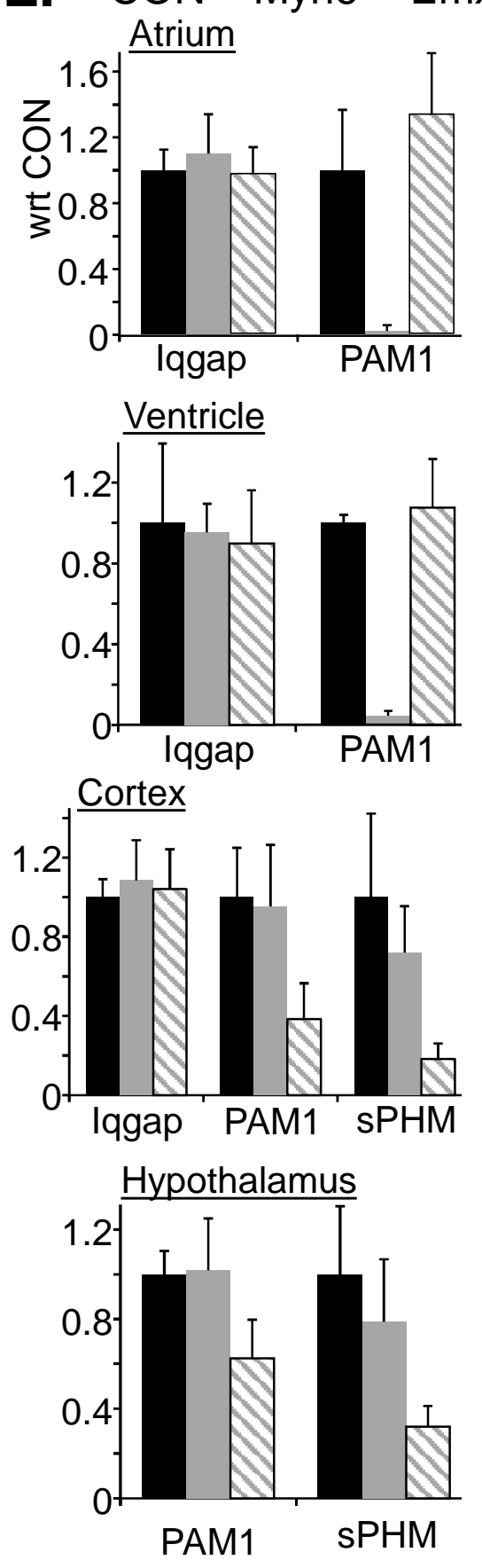


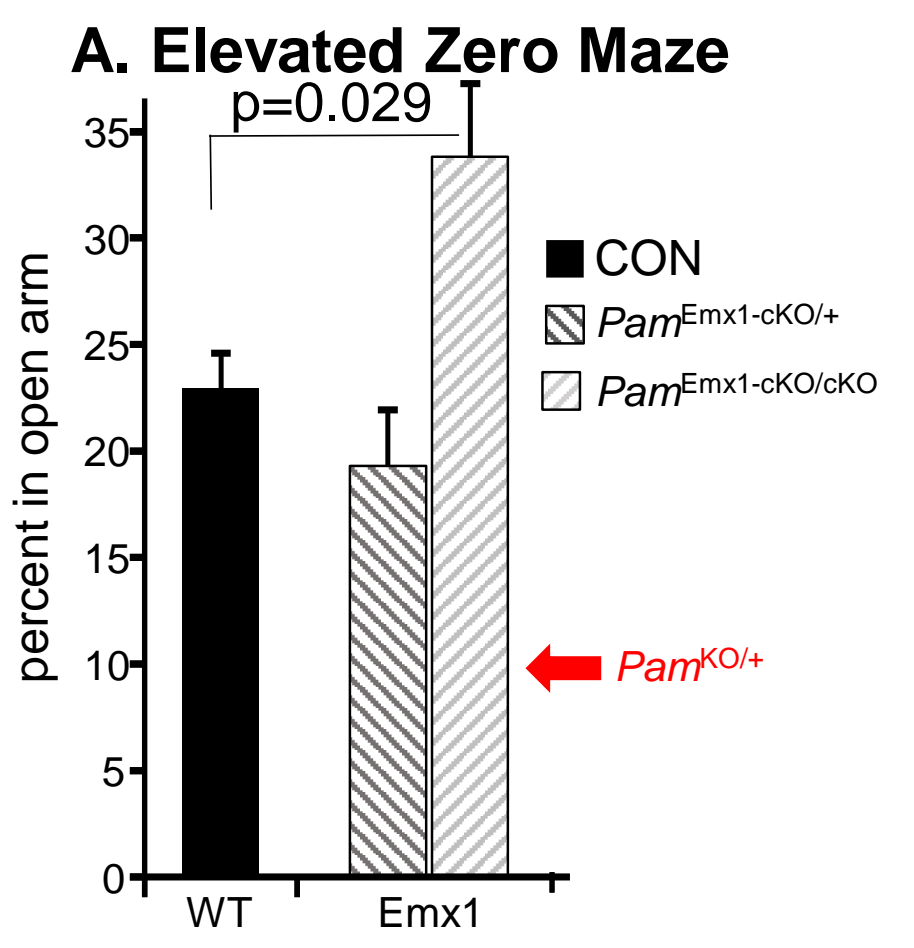

\section{B. Locomotor Response to Cocaine}

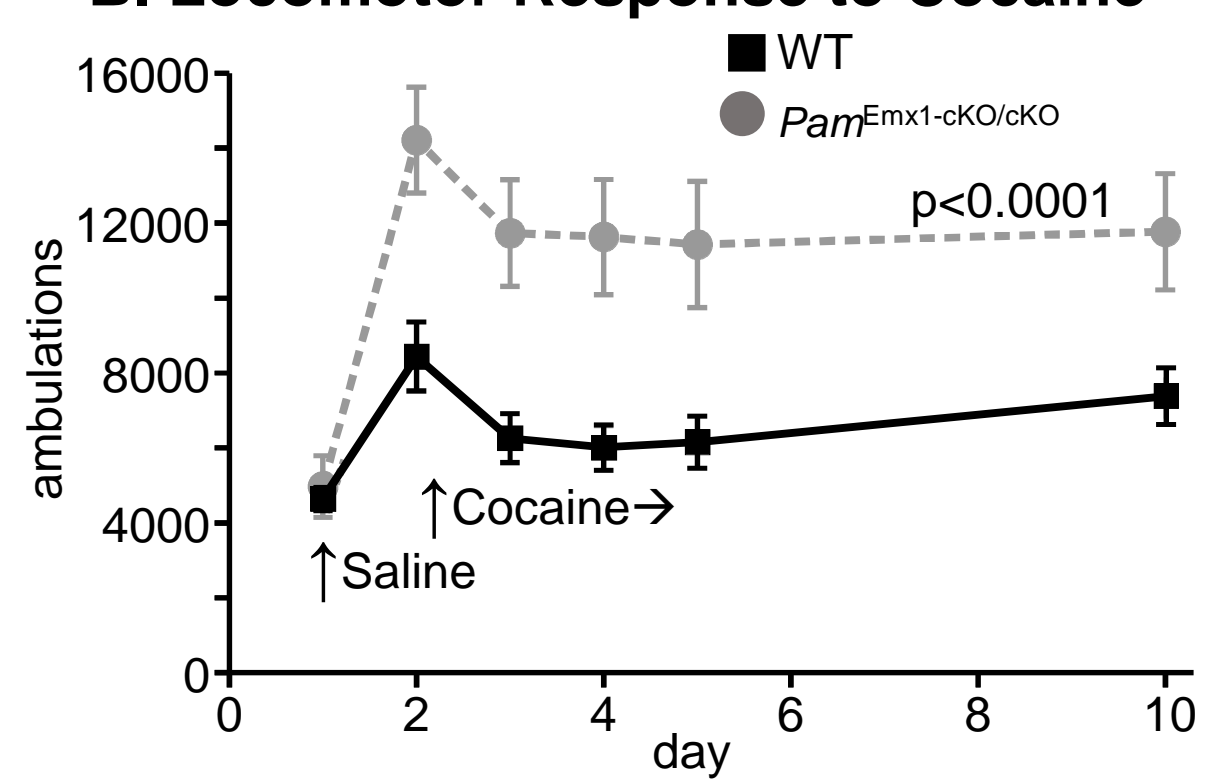

C. Core Temperature

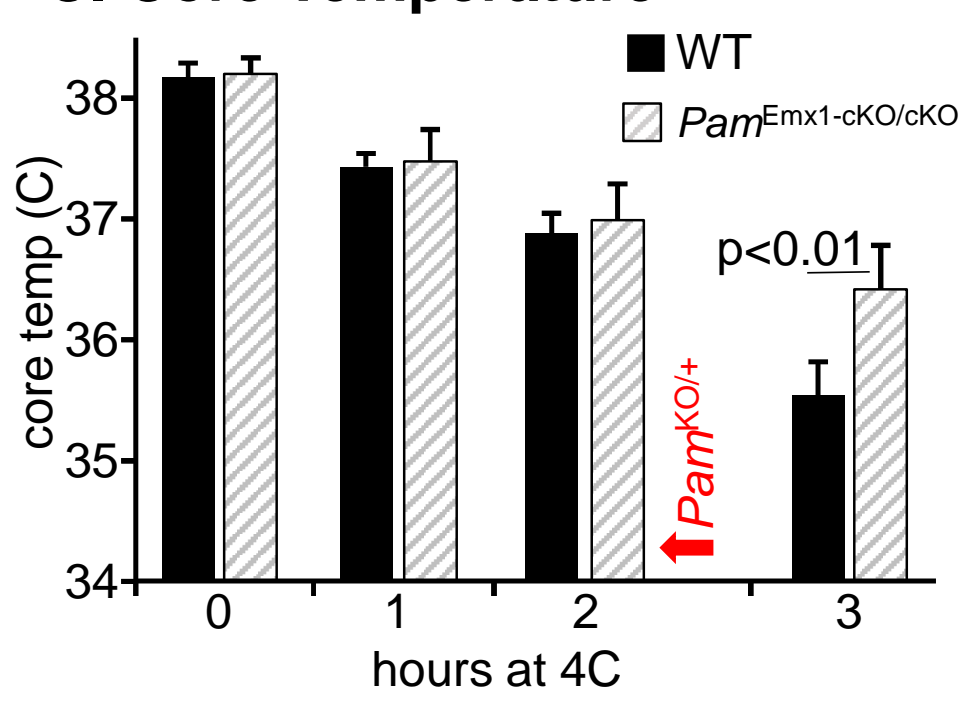


\begin{tabular}{l|l|l}
$50 \mu \mathrm{m}$ & CA3 & Cortex layer 2 \\
\hline
\end{tabular}

$20 \mu \mathrm{m} /$ Cortex layer 2 KO

ลे $\mathrm{mf}$ $\div \mathrm{mf}$

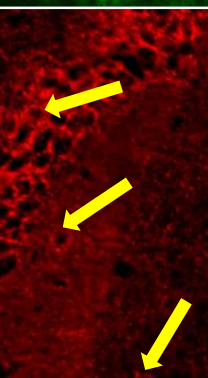

A.
B.

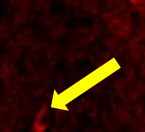

$10=$ Cortex

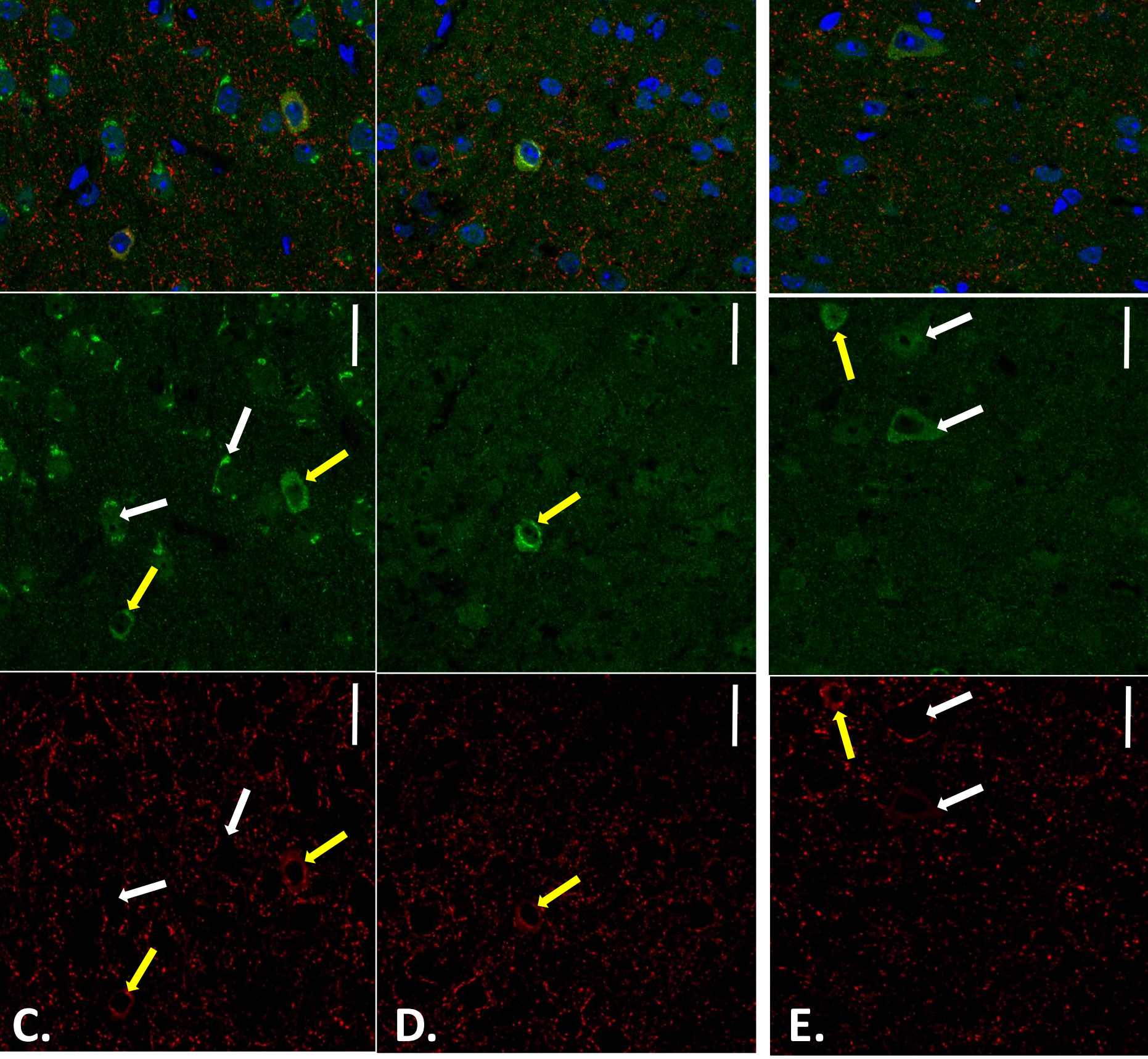


A. Elevated Zero Maze

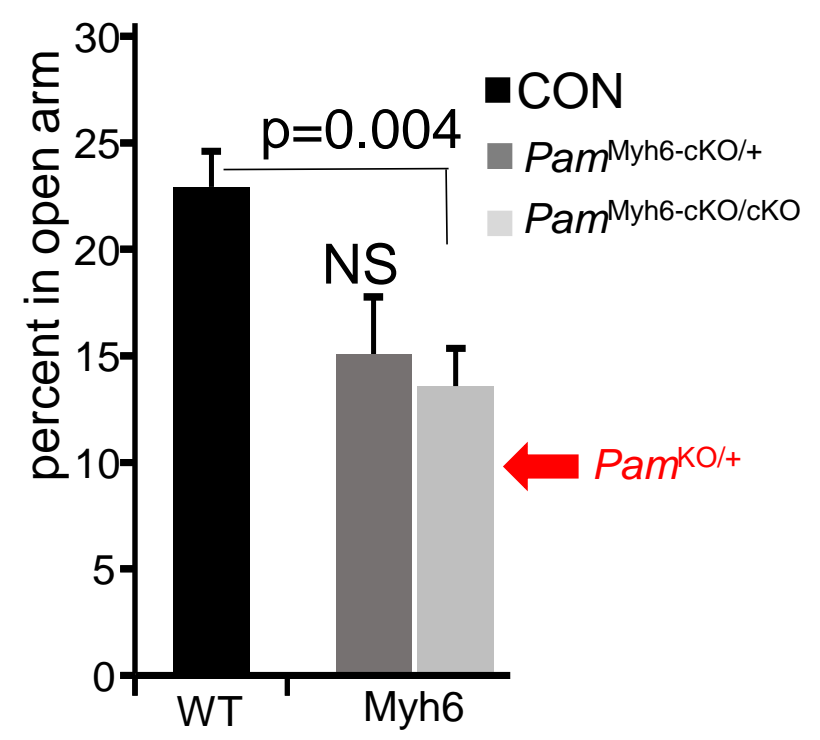

C. Core Temperature

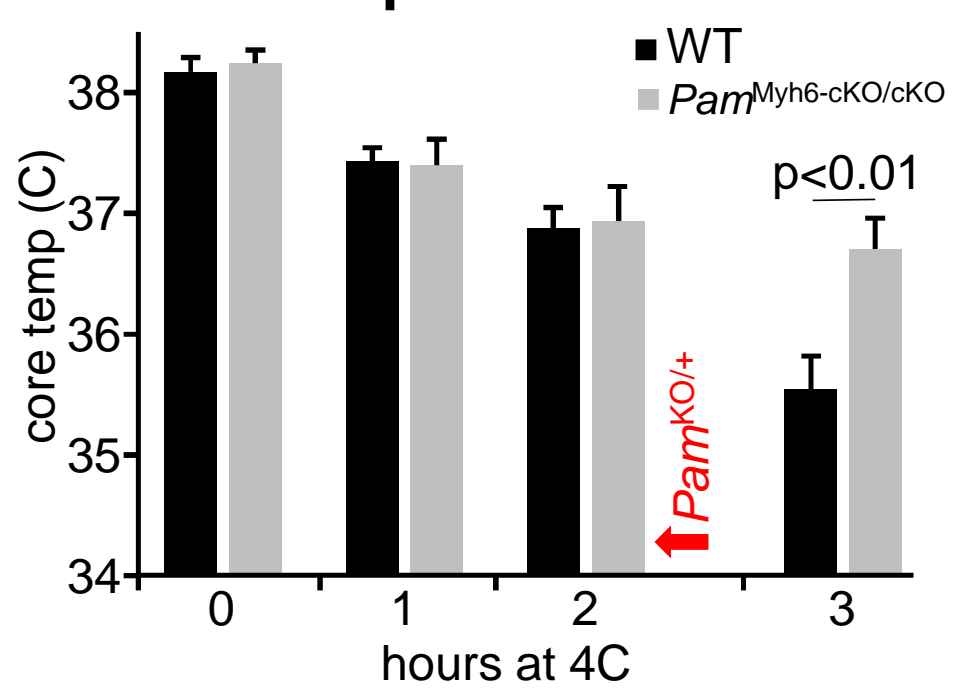

\section{B. Locomotor Response to Cocaine}

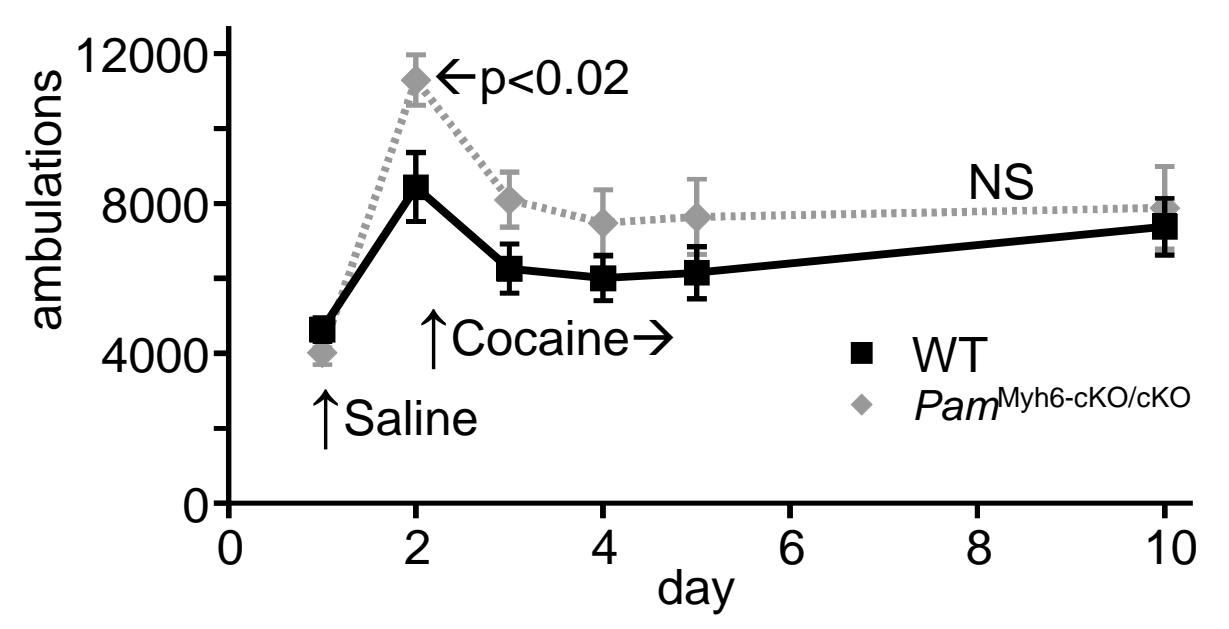

D. Tail Temperature

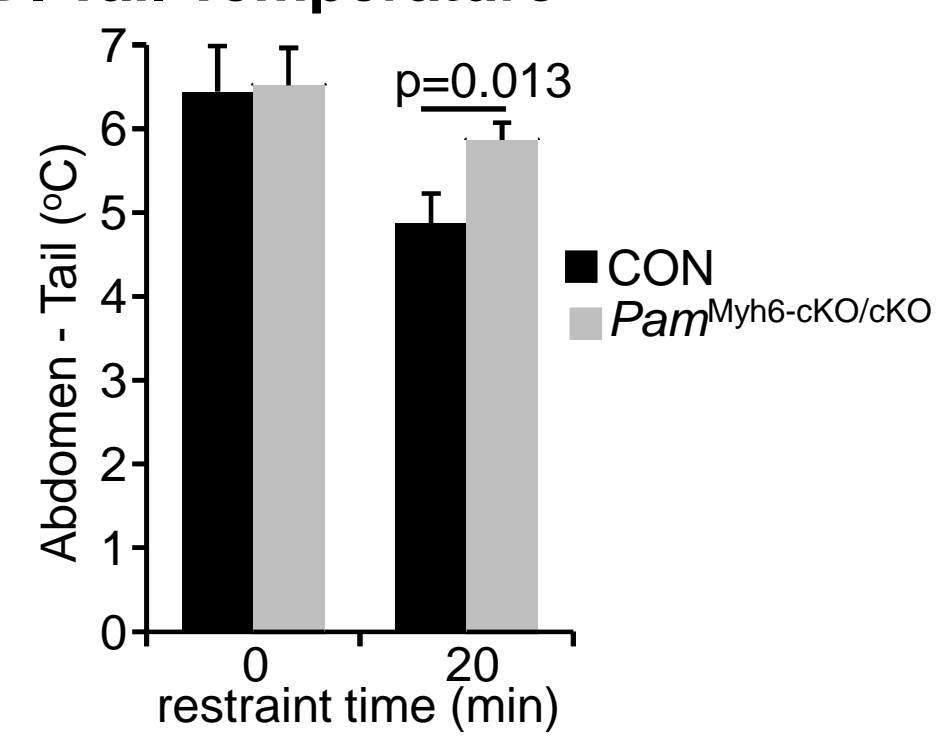




\section{A. N-terminal \& C-terminal proANP}

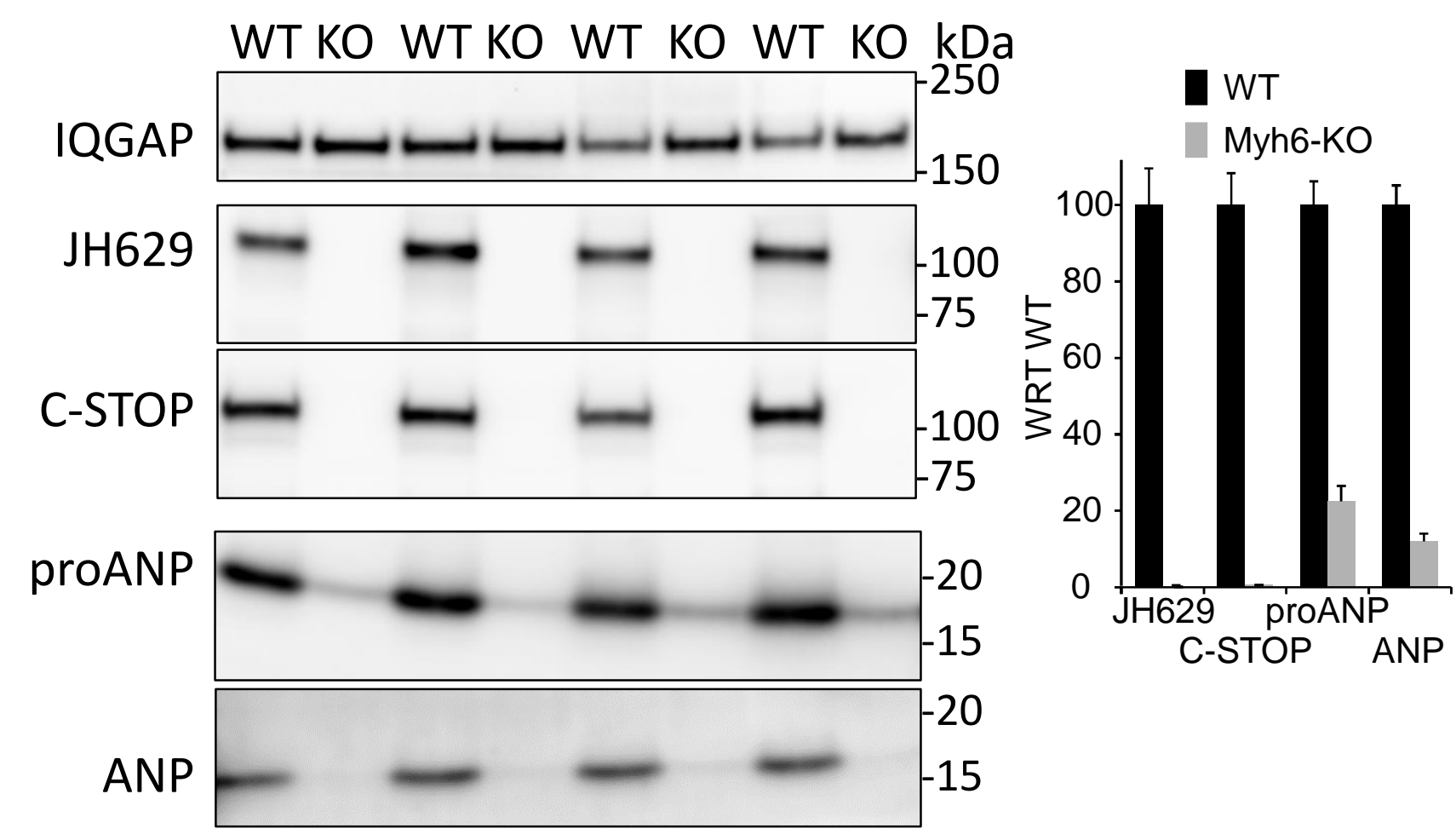

B. ANP ELISA

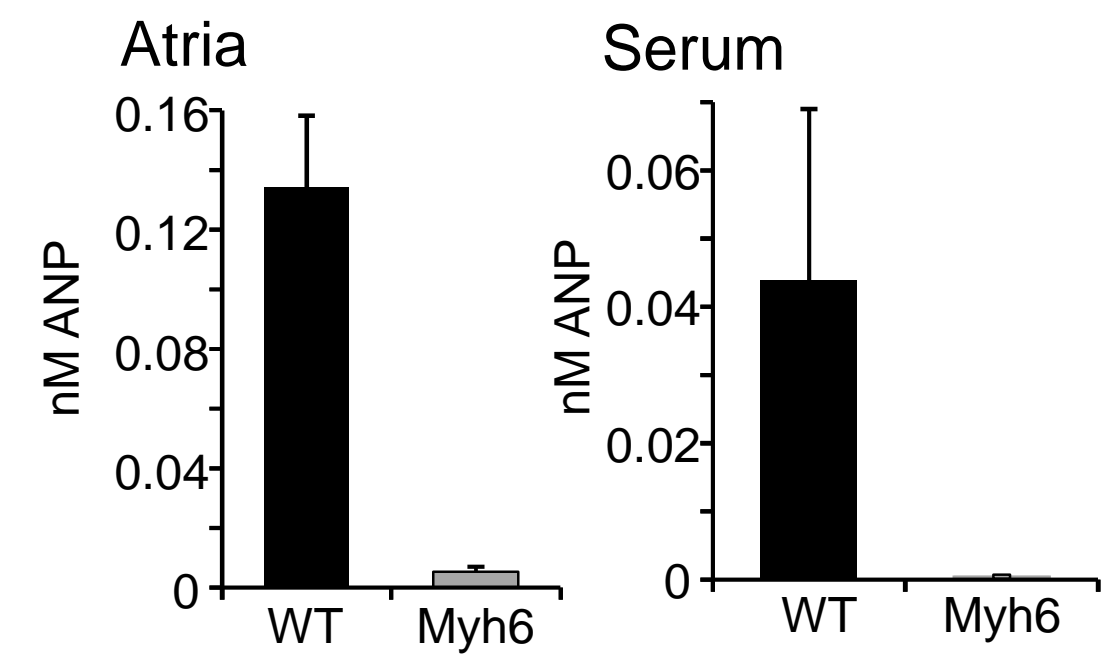

C. Serum PHM

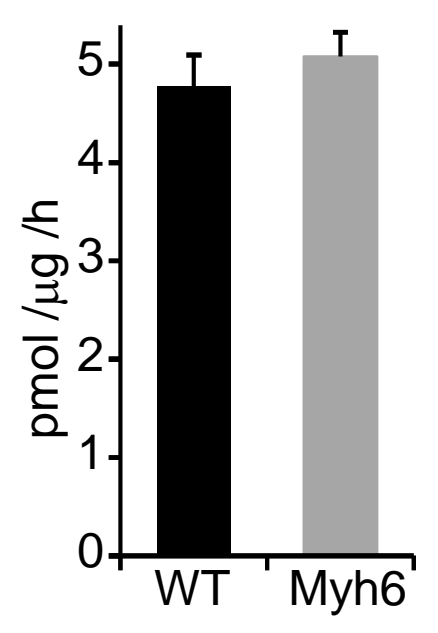

D. Salt loading / Blood pressure

... Normal Salt | High Salt | Normal Salt BP: $0 \cdots 0000 \bullet \bullet \bullet \bullet \bullet \bullet \bullet 0000000$ (day) $\quad 0 \quad 3456789101112 \ldots \ldots 18$ Ma
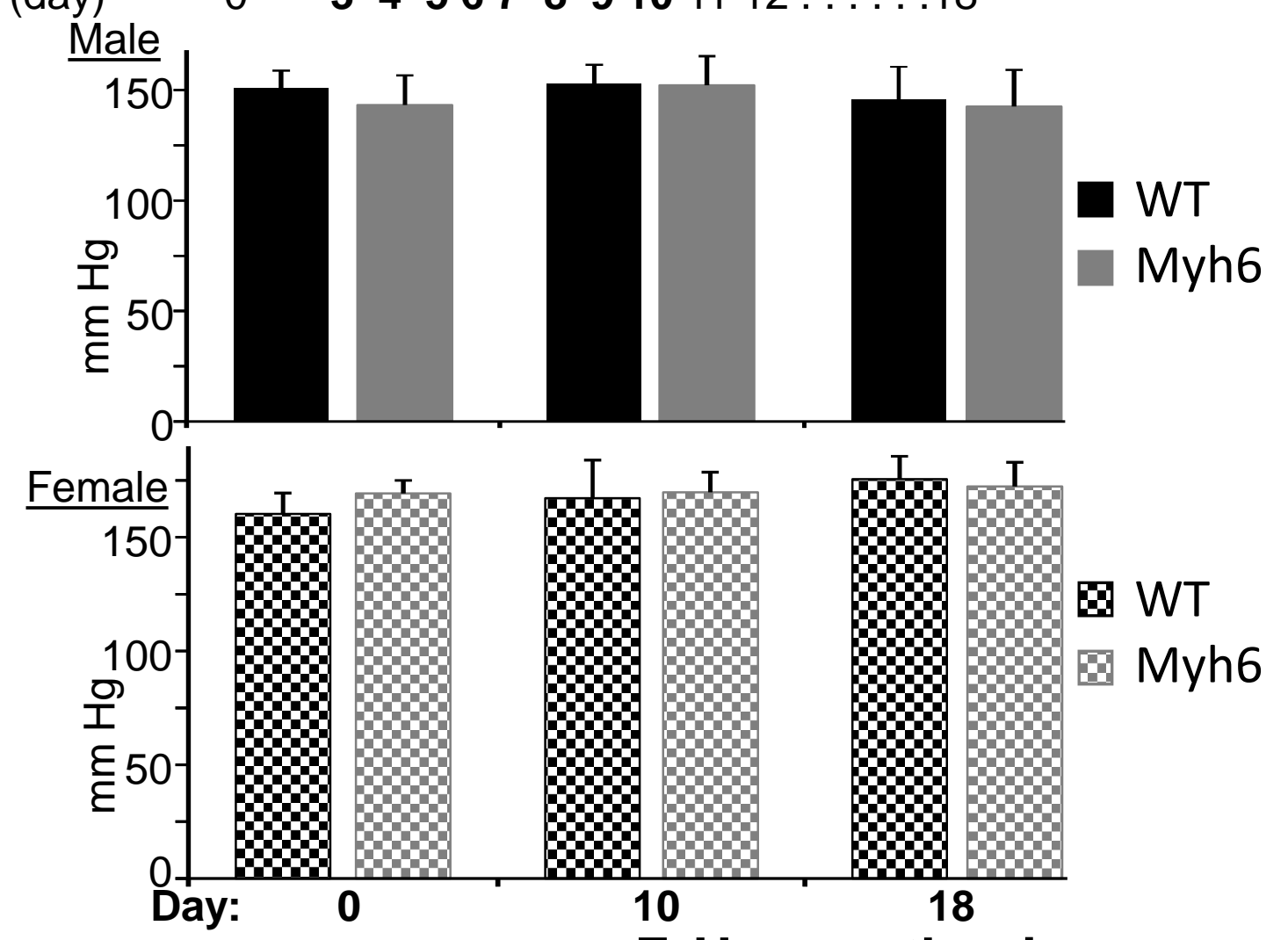

Q WT

Myh6
F. Hexamethonium

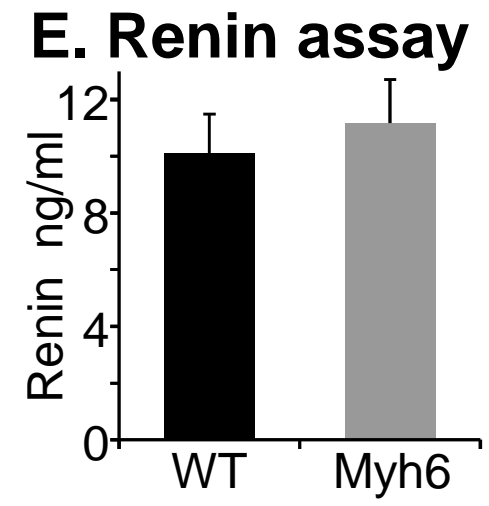

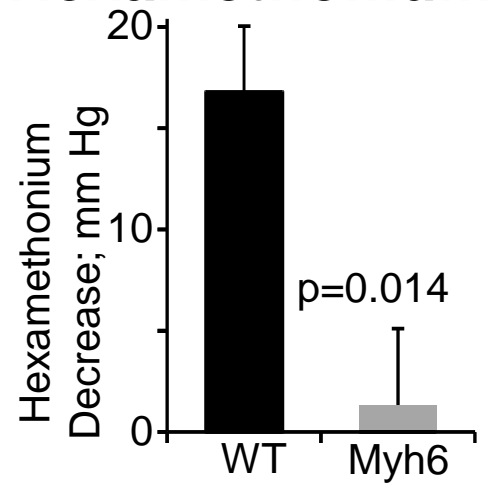


A. $\quad-\log _{10}(p)$

(L) Best3-。 67

Serpine1-
-Arxes2

(R)

Zbtb16-
Pmel-

Cnksr1 Per3-0

Per2-Per1-e os

Tnnt3-

$$
\text { Tyrp1 }
$$

Snhg11-。

Gpr17-

Bigheart-

-

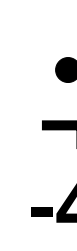

$-$ Low PAM $\leftarrow \log _{2}(\mathrm{Wt} / \mathrm{Ko}) \rightarrow$ high PAM
B. Apelin Network

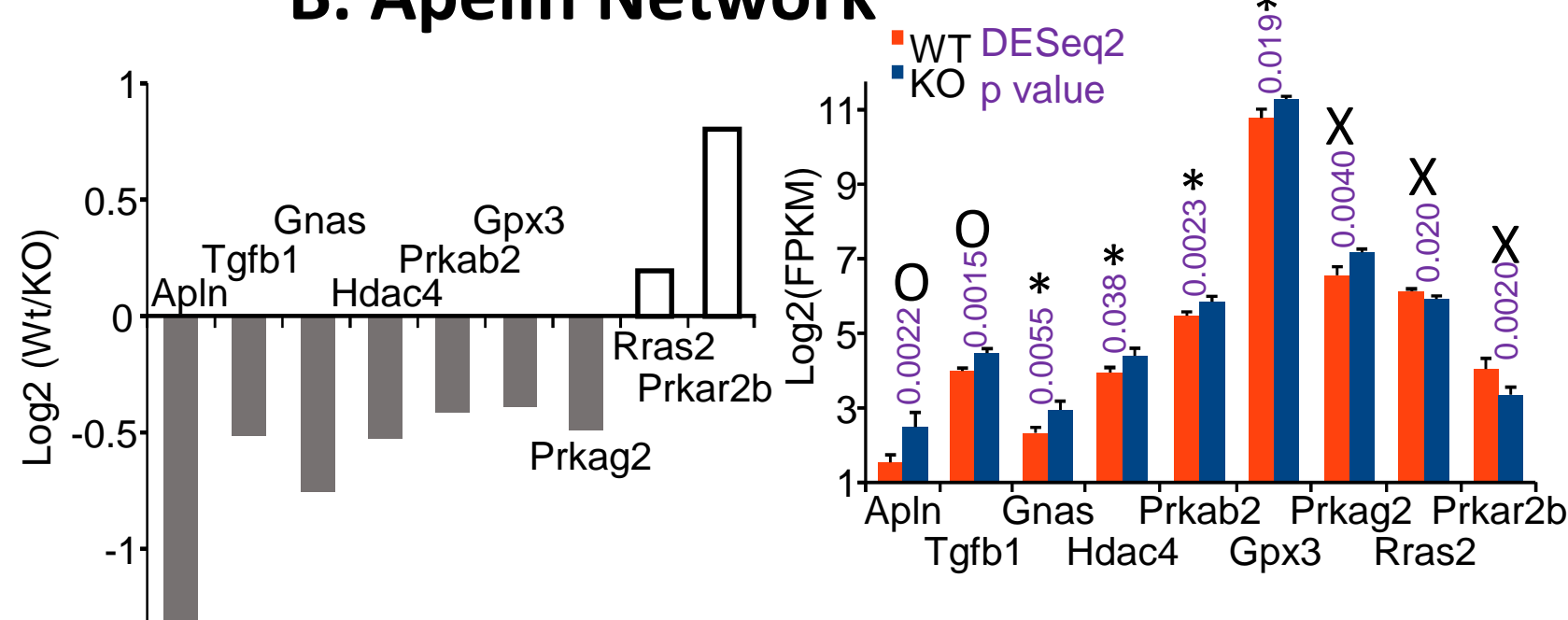

\section{Circadian Network}
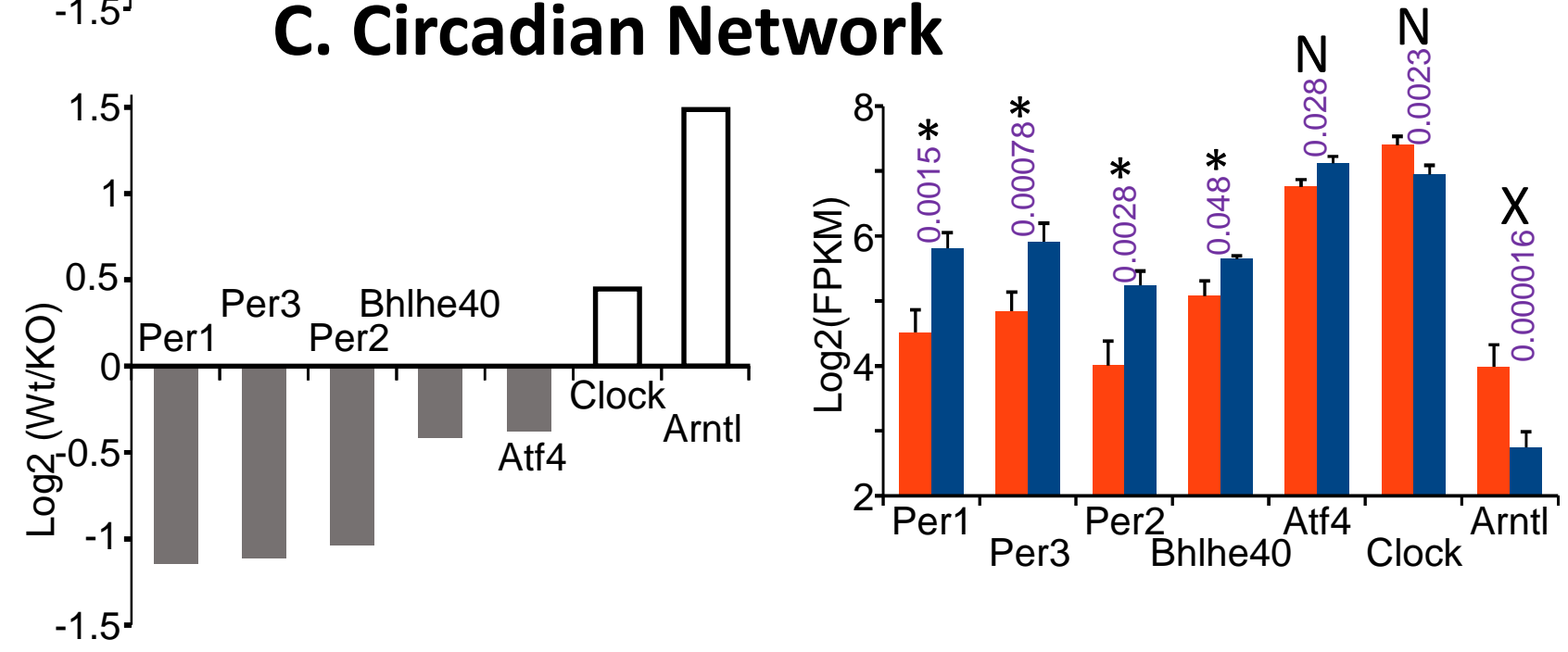